\title{
ANÁLISE DAS VARIAÇÕES FLORÍSTICAS E ESTRUTURAIS DA COMUNIDADE ARBÓREA DE UM FRAGMENTO DE FLORESTA SEMIDECÍDUA ÀS MARGENS DO RIO CAPIVARI, LAVRAS-MG ${ }^{1}$
}

\author{
Josival Santos Souza², Fernando Del Bon Espírito-Santo ${ }^{3}$, Marco Aurélio Leite Fontes ${ }^{4}$, Ary Teixeira de \\ Oliveira-Filho ${ }^{4}$ e Luciana Botezelli ${ }^{5}$
}

\begin{abstract}
RESUMO - Realizou-se um estudo das variações florísticas e estruturais da comunidade arbórea em um fragmento de Floresta Estacional Semidecídua situado às margens do rio Capivari, em Lavras, Minas Gerais, com o objetivo de analisar as correlações entre variáveis ambientais (edáficas, topográficas e morfométricas do fragmento) e a distribuição das espécies arbóreas. Procurou-se, também, ampliar o conhecimento sobre a composição florística e a estrutura fitossociológica das comunidades arbóreas da região do alto rio Grande. As espécies arbóreas foram amostradas em coletas extensivas na área e intensivas dentro de 28 parcelas de $20 \times 20 \mathrm{~m}$, tendo sido considerados apenas os indivíduos com DAP $\geq 5 \mathrm{~cm}$. As parcelas foram distribuídas em cinco transeções, dispostas paralelamente à inclinação predominante do terreno. As variáveis ambientais foram obtidas por meio do levantamento topográfico do fragmento e de análises químicas e granulométricas de amostras dos solos. As correlações entre distribuição das abundâncias das espécies e as variáveis ambientais nas parcelas foram avaliadas por análise de correspondência canônica (CCA). A listagem florística registrou 166 espécies, sendo 140 encontradas dentro das parcelas. A comunidade arbórea apresentou um elevado índice de diversidade de Shannon $\left(H^{\prime}=4,258\right.$ nats/indivíduo), correlacionado à baixa dominância ecológica (alta equabilidade de Pielou, $J^{\prime}=0,862$ ) e, possivelmente, à alta heterogeneidade ambiental local. A CCA demonstrou que a heterogeneidade ambiental do fragmento é caracterizada principalmente pela topografia acidentada e pelas variações de fertilidade, granulometria e regime hídrico dos solos, sendo este último o mais fortemente correlacionado com a distribuição das espécies. Muitas espécies arbóreas mostraram clara preferência por dois habitats: a baixa encosta, com solos mais úmidos e férteis, e a alta encosta, com solos menos úmidos e férteis e mais sujeita ao efeito borda.
\end{abstract}

Palavras-chave: Floresta Estacional Semidecidual, análise multivariada, relações espécie-ambiente, comunidade arbórea e diversidade de espécies.

\section{ANALYSIS OF THE FLORISTIC AND STRUCTURAL VARIATIONS OF A TREE COMMUNITY IN A TROPICAL SEMIDECIDUOUS FOREST FRAGMENT ON THE MARGINS OF THE CAPIVARI RIVER, LAVRAS, SOUTHEASTERN BRAZIL}

ABSTRACT - A study of the floristic and structural variations of a tree community was carried out in a tropical
semideciduous forest fragment, located on the margins of the Capivari river, in Lavras, Minas Gerais, Brazil, to
analyze the correlations between environmental variables (related to soil, topography and fragment shape) and

1 Recebido para publicação em 8.5.2001.

Aceito para publicação em 19.2.2003.

Este trabalho integra o Subprojeto Estratégias para conservação e manejo da biodiversidade em fragmentos de florestas semidecíduas executado pela EMBRAPA Recursos Genéticos, pela Universidade Federal de Lavras (UFLA) e pela Universidade de Brasília (UnB), e faz parte do Projeto de Conservação e Utilização Sustentável da Diversidade Biológica Brasileira (PROBIO), supervisionado pelo Ministério do Meio Ambiente (MMA), gerido pelo Conselho Nacional de Desenvolvimento Científico e Tecnológico (CNPq) e apresentado pelo governo brasileiro ao GEF/BIRD.

2 Pós-graduação, Laboratório de Ciências Ambientais, CBB da Universidade Estadual do Norte-Fluminense Darcy Ribeiro UENF, Av. Alberto Lamego 2000, 28015-620 Campos dos Goytacazes-RJ. ${ }^{3}$ Pós-graduação, Instituto Nacional de Pesquisas Espaciais, Av. dos Astronautas, 1758, 12201-027 São José dos Campos-SP. ${ }^{4}$ Professores e ${ }^{5}$ bolsista DTI/CNPq/PROBIO, Departamento de Ciências Florestais da Universidade Federal de Lavras - UFLA, 37200-000 Lavras-MG. 
the distribution of tree species. The study also aimed to increase the understanding on the floristic composition and phytosociological structure of tree communities in the upper Rio Grande region. Tree species were sampled in extensive collecting excursions as well as through 28 sample plots of $20 \times 20 \mathrm{~m}$, where all individuals with $d b h \geq 5 \mathrm{~cm}$ were registered. The plots were distributed into five transects placed parallel to the predominant slope of each site. The environmental variables were obtained through a topographic survey of the fragment and chemical and textural analyses of soil samples. The correlations between the distribution of species abundance and environmental variables in the plots were assessed by canonical correspondence analysis (CCA). The floristic checklist contained 166 species, out of which 140 were found inside the sample plots. The tree community produced a high Shannon diversity index $\left(H^{\prime}=4.258\right.$ nats/individual), correlated to low ecological dominance (high Pielou evenness, $J^{\prime}=0.862$ ), and possibly to high local environmental heterogeneity. The CCA showed that the environmental heterogeneity of the fragment is characterized mainly by the steep topography and by the variations in soil fertility, texture and ground water regime. The latter is most strongly correlated with the distribution of the tree species. The analysis indicated that many tree species in the fragment show preference for either of the following two habitats: the lower slope, with moister and more fertile soils; and the upper slope, with less moist and fertile soils, and more liable to edge effects.

Key words: $\quad$ Tropical seasonal forest, multivariate analysis, species-environment relationship, tree community and species diversity.

\section{INTRODUÇÃO}

O Brasil apresenta uma expressiva diversidade de ecossistemas florestais, devido à grande área física e à diversidade de climas e solos existentes em seu território (Leitão-Filho, 1987). O Estado de Minas Gerais é possuidor da maior variedade de formações vegetais do País, em decorrência de suas diversas condições geológicas, topográficas e climáticas (Mello-Barreto, 1942). No entanto, essa cobertura vegetal natural está, hoje, quase totalmente reduzida a remanescentes esparsos, com a cobertura florestal, em particular, correspondendo a apenas cerca de $2 \%$ do território mineiro (CETEC, 1983). Na região do alto rio Grande, sul de Minas Gerais, a cobertura vegetal primitiva encontra-se reduzida a fragmentos de florestas e cerrados, em sua maioria bastante perturbados pelo fogo, pela pecuária extensiva ou pela retirada seletiva de madeira (Oliveira-Filho \& Machado, 1993). As florestas semidecíduas, em particular, foram drasticamente reduzidas na região, uma vez que sua ocorrência coincide com solos mais férteis e úmidos e, portanto, mais visados pela agropecuária (Eiten, 1982).

As matas ciliares, definidas aqui como florestas associadas a cursos d'água, proporcionalmente têm ampla distribuição geográfica, mas recobrem uma superfície pequena na paisagem. Destacam-se ainda pela fragilidade e particular importância para preservação da fauna e da flora terrestre e aquática. Dados de vários trabalhos realizados em bacias e microbacias hidrográficas têm evidenciado que a presença da mata ciliar é garantia de estabilidade e de menor concentração de sedimentos no deflúvio (Lima \& Zakia, 2000). Apesar disto, a erradicação do ecossistema ciliar, principalmente nas regiões mais populosas do Brasil, tem ocorrido em flagrante desrespeito à legislação.

Apesar de sua inegável importância ambiental, as matas ciliares se aproximaram de uma virtual erradicação em várias partes do Brasil. Entre os inúmeros fatores que têm contribuído para este fato, destacam-se, pela gravidade, as derrubadas, os incêndios, os represamentos e o assoreamento dos rios devido à erosão (Gibbs et al., 1980). A situação crítica em que se encontram as matas ciliares do centro-sul do Brasil motivou, nos últimos anos, uma série de iniciativas voltadas para sua conservação ou recuperação. Tais iniciativas impulsionaram Simpósios sobre Matas Ciliares: o primeiro deles realizado em São Paulo, em 1989 (Barbosa, 1989), o segundo em Ribeirão Preto, em 1995 (SOCIEDADE BOTÂNICA DO BRASIL, 1995), o terceiro em Brasília, em 1996 (Imaña-Encinas \& Kleinn, 1997) e o quarto em Belo Horizonte, em 1999 (Davide, 1999). Tais eventos deixaram claro para os pesquisadores envolvidos que estudos detalhados sobre a composição florística e a ecologia das comunidades arbóreas das matas ciliares remanescentes são fundamentais para embasar quaisquer iniciativas no 
sentido de proteger, enriquecer, recuperar ou reconstituir este tipo de vegetação (Rodrigues \& Nave, 2000).

Somente a partir da década de 70 que estudos florísticos, fitossociológicos e ecológicos de matas ciliares foram intensificados no Brasil, particularmente nos Estados de São Paulo e Minas Gerais, com o intuito de fornecer subsídios para proteção e enriquecimento de matas ciliares (Rodrigues, 1991). Em Minas Gerais, estudos mais detalhados e específicos sobre comunidades arbóreas de matas ciliares eram incipientes ou ausentes na literatura até o início da década de 90. Desde então, vários trabalhos têm se multiplicado no Estado, por exemplo, na Zona da Mata (Meira Neto et al., 1997a, b, c, 1998), no Triângulo Mineiro (Schiavini, 1997; OliveiraFilho et al., 1997a, 1998), no Vale do Rio Doce (Carvalho et al., 2000), no baixo Paranaíba (Carvalho, 1996b; Vilela et al., 1998), no Alto São Francisco (Carvalho et al., 1999, 2000; Vilela et al., 1998) e no alto e médio rio Grande (Carvalho et al., 1995, 1996a; Oliveira-Filho et al., 1994d, 1997a; Van Den Berg \& Oliveira-Filho, 1999, 2000; Vilela et al., 1999).

Dessa forma, torna-se urgente a necessidade de avaliar a diversidade biológica contida nos atuais fragmentos de mata ciliar, por meio de sua quantificação, bem como compreender a organização espacial da comunidade nos fragmentos e a direção das mudanças nos processos ecológicos, o que permitirá avaliar os potenciais de perdas e conservação dos recursos naturais a longo prazo. A região do alto rio Grande, no sul de Minas Gerais, é um dos focos atuais do Projeto de Conservação e Utilização Sustentável da Diversidade Biológica Brasileira (PROBIO), onde atua o subprojeto 'Estratégias para conservação e manejo da biodiversidade em fragmentos de florestas semidecíduas', executado pela EMBRAPA Recursos Genéticos, Universidade Federal de Lavras (UFLA) e Universidade de Brasília (UnB). O presente trabalho integra este subprojeto e teve como objetivos centrais: a) quantificar a diversidade de espécies arbóreas e b) avaliar os principais fatores condicionantes da distribuição destas espécies em um dos 17 fragmentos de Floresta Estacional Semidecidual estudados na região, conhecido como Mata do Rio Capivari.

\section{MATERIAL E MÉTODOS}

\subsection{Caracterização da Área de Estudo}

O estudo foi conduzido em um fragmento florestal com uma área de 13,6 ha, localizado ao longo da margem esquerda do curso do rio Capivari $\left(21^{\circ} 18^{\prime} \mathrm{S}\right.$ e $\left.44^{\circ} 20^{\prime} \mathrm{W}\right)$, afluente do rio Grande, no município de Lavras-MG, com acesso pela rodovia BR 265, que liga Lavras a Barbacena. As altitudes no fragmento variam de 920 a $940 \mathrm{~m}$ e a topografia é bastante acidentada, com declividades entre 10 e $45^{\circ}$. Os solos predominantes são os Argissolos e ocorrem manchas de Cambissolos e Neossolos Flúvicos nas margens do rio Capivari. O clima do município de Lavras é do tipo Cwb de Köppen (mesotérmico com verões brandos e suaves e estiagem de inverno). As médias anuais de precipitação e temperatura são de $1.493 \mathrm{~mm}$ e $19,3{ }^{\circ} \mathrm{C}$, respectivamente (Vilela \& Ramalho, 1979).

Segundo a classificação do IBGE (Veloso et al., 1991), a maior parte do fragmento é classificada como Floresta Estacional Semidecidual Montana, por se localizar principalmente na encosta do morro. Ocorrem, ainda, faixas estreitas de Floresta Estacional Semidecidual Aluvial nas áreas adjacentes à margem do rio e estas estão sujeitas a inundações periódicas. $\mathrm{O}$ fragmento divide-se em duas partes quanto ao histórico de perturbação. A parte sudoeste, com cerca de 7 ha, é formada pela floresta madura, com evidências de impactos localizados causados pela retirada seletiva de pequenas árvores. A parte norte, com 6,6 ha, é constituída de floresta secundária que está se recuperando de um corte raso sofrido há mais de 50 anos. O presente estudo foi desenvolvido apenas na parte madura da floresta.

\subsection{Levantamento Estrutural da Comunidade Arbórea}

Para realização deste estudo, foram utilizadas parcelas contíguas, alinhadas em transeções, com o objetivo de representar as maiores variações nos gradientes presumidos para a comunidade arbórea do fragmento. Cada transeção foi disposta paralelamente à inclinação predominante do terreno. Segundo Rodrigues (1989), o método de parcelas contíguas para o estudo estrutural da comunidade arbórea é vantajoso em áreas com grande heterogeneidade ambiental, porque permite avaliar correlações mais estreitas da vegetação com os fatores abióticos e por fornecer subsídios para o entendimento da distribuição espacial das espécies.

As parcelas foram dispostas em cinco transeções, distribuídas de modo que elas ficassem o mais eqüidistantes possível. Todas começavam próximo à margem do rio e terminavam na borda do fragmento, junto à

R. Árvore, Viçosa-MG, v.27, n.2, p. 185-206, 2003 
pastagem. Foram instaladas 28 parcelas de $20 \times 20 \mathrm{~m}$, totalizando uma área amostral de 1,12 ha (Figura 1). Para instalação das parcelas, foram utilizadas trenas para medir as distâncias horizontais e bússola para orientar o alinhamento do contorno das parcelas. A inclinação do terreno foi corrigida durante as medições das distâncias horizontais, nivelando as extremidades da trena. Os vértices das parcelas foram demarcados com estacas de PVC e as laterais, com fitilhos de náilon. Em cada parcela, todos os indivíduos com diâmetro à altura do peito (DAP) $\geq 5 \mathrm{~cm}$, exceto lianas e indivíduos mortos, foram etiquetados com plaquetas de alumínio numeradas. Para cada indivíduo amostrado foi mensurada a circunferência à altura do peito (CAP) com o uso da fita métrica e também estimada a altura por comparação com o podão de $13 \mathrm{~m}$.

\subsection{Coleta, Manuseio e Identificação do Material Botânico}

As coletas do material botânico foram realizadas nos meses de fevereiro a dezembro de 1997, como parte do levantamento estrutural nas parcelas, sendo acrescidas de coletas de outros indivíduos em caminhadas em todo o fragmento. Os materiais botânicos coletados foram prensados, secos, montados (herborizados) e incorporados ao Herbário da Universidade Federal de Lavras (ESAL). As identificações foram feitas através de comparações com exsicatas existentes nos Herbários ESAL, UEC (Universidade Estadual de Campinas), RB (Jardim Botânico do Rio de Janeiro) e SP (Instituto de Botânica de São Paulo), bem como através de consultas à literatura e aos especialistas daquelas instituições. A classificação das espécies em famílias seguiu o sistema do Angiosperm Phylogeny Group (APG, 1998).

\subsection{Topografia, Solos e Variáveis Morfométricas do Fragmento}

Foi efetuado um levantamento topográfico da área com o auxílio de trenas e de um hipsômetro de BlumeLeiss, para medir o desnível do terreno, e de uma bússola para indicar o caminhamento. A partir deste levantamento foram construídas curvas de nível e uma grade de superfície (Figura 1).

De posse das cotas topográficas dos vértices das parcelas, foram calculadas duas variáveis topográficas por parcela: cota média, obtida a partir da média dos quatro vértices, e desnível, obtido pela diferença entre as cotas máxima e mínima, seguindo a metodologia proposta por Oliveira-Filho et al. (1994c, e) e Van Den Berg \& Oliveira-Filho (1999).

Duas variáveis morfométricas do fragmento florestal foram obtidas para cada parcela: ‘borda do fragmento' e 'margem do rio'. A 'borda do fragmento' é vista neste estudo como uma variável complexa que engloba os vários aspectos do efeito borda, como redução da umidade do solo e maior exposição ao sol e a rajadas de vento. Já a 'margem do rio', que é de fato outro tipo de borda, constitui outra variável complexa, englobando maior umidade do solo, exposição ao sol e suscetibilidade a cheias ocasionais.

A extensão para o interior de um fragmento até onde é possível detectar os efeitos de uma borda é ainda bastante polêmica, e uma das dificuldade tem sido produzir uma medida geométrica eficiente para avaliar o efeito borda (Murcia, 1995). A influência de uma borda sobre qualquer ponto no interior da floresta não deve ser avaliada a partir de uma simples medida de distância até a borda mais próxima, porque esta desconsidera o contorno da borda e a influência de vários pontos ao longo deste contorno (Malcolm, 1994). Desta maneira, as duas variáveis morfométricas foram produzidas de acordo com o método utilizado por Oliveira-Filho et al. (1997b) na Reserva Florestal da UFLA. Este consiste do comprimento linear do contorno do fragmento, medido entre dois (ou mais) pontos de interceção com um círculo, cujo raio tem origem no centro da parcela. $\mathrm{O}$ comprimento deste raio representaria o raio de ação máxima do efeito borda (ou margem) sobre a comunidade arbórea, e tendo sido fixado em $70 \mathrm{~m}$ pelos autores citados. No entanto, neste estudo o raio foi ampliado para $100 \mathrm{~m}$, porque, segundo Laurence et al. (1998), esta distância definiria a faixa em que as bordas influenciam mais fortemente a distribuição das plantas dentro de fragmentos florestais da Amazônia Central.

Os solos de cada parcela foram classificados segundo o novo Sistema Brasileiro de Classificação de Solo (EMPRESA BRASILEIRA DE PESQUISA AGROPECUÁRIA - EMBRAPA, 1999) até o nível de subgrupo (4º nível categórico) e incluindo os grupamentos texturais e as classes de drenagem. Esta classificação foi feita no campo pelo Dr. Nilton Curi, do Departamento de Ciências do Solo da Universidade Federal de Lavras. Foram reconhecidas três categorias: a) Cambissolo Háplico Distrófico típico moderadamente drenado e de textura média; b) Argissolo Vermelho Distrófico típico 
acentuadamente drenado e de textura média a argilosa; e c) Argissolo Vermelho Distrófico latossólico bem drenado e com textura argilosa. Para simplificar, estes solos serão denominados, a partir daqui, de Cambissolo, Argissolo A e Argissolo B. Sua distribuição é indicada na Figura 1.

Foi coletada, em cada parcela, uma amostra composta do solo superficial (0-20 cm de profundidade) com cerca de 500 g. Cada amostra composta foi constituída de três subamostras coletadas dentro de cada parcela. As amostras de solo foram armazenadas em sacos plásticos, identificadas e enviadas para o Laboratório de Análise de Solos da Universidade Federal de Lavras para obtenção das seguintes variáveis: $\mathrm{pH}$ em água; teores de potássio $(\mathrm{K})$, fósforo $(\mathrm{P})$, cálcio $(\mathrm{Ca})$, magnésio $(\mathrm{Mg})$ e alumínio (Al); soma de bases (SB), saturação por bases (V) e matéria orgânica (MO); e proporções de areia, silte e argila. Os procedimentos de laboratório seguiram o protocolo da EMBRAPA (1997).

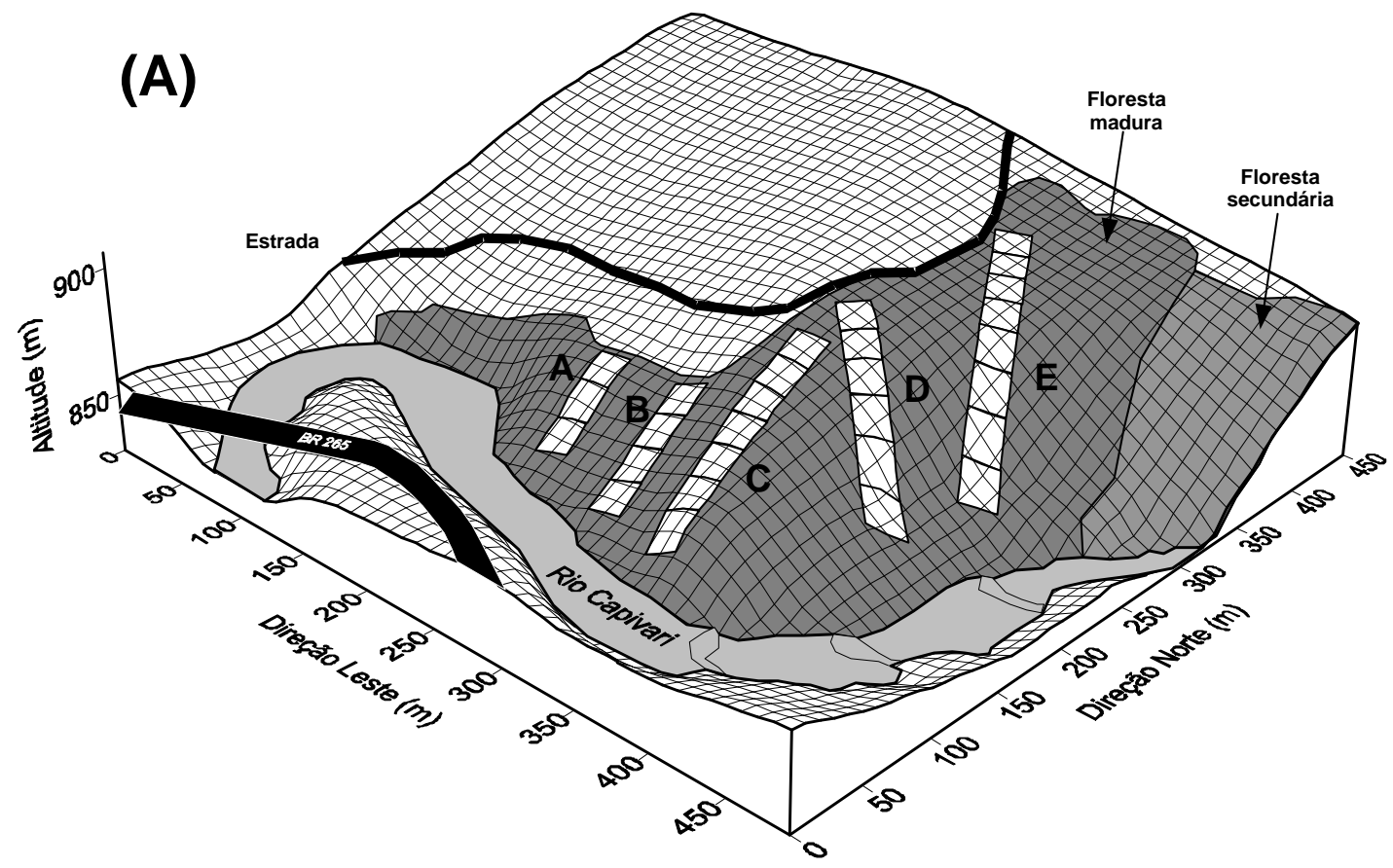

(B)

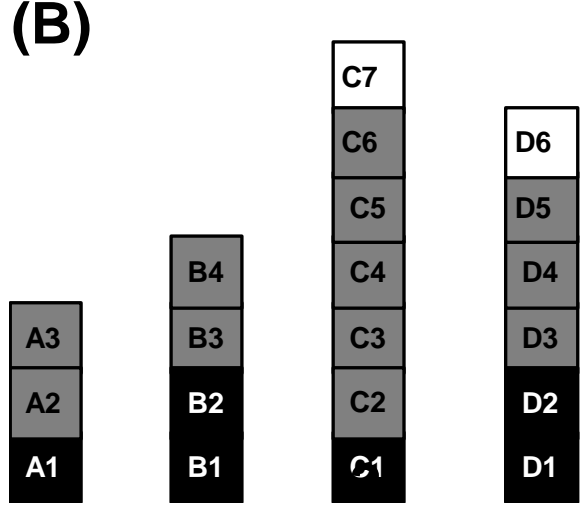

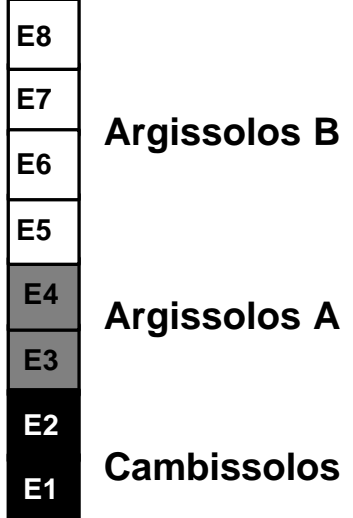

Figura 1 - (A) Grade de superfície da área de estudos ilustrando a distribuição das cinco transeções amostrais (A-E) e de suas parcelas de $20 \times 20 \mathrm{~m}$. O espaçamento entre as linhas da grade é de $10 \mathrm{~m}$; (B) identificação das parcelas e classificação dos sol os. Figure 1 - (A) Surfacegrid of thestudy area showing thedistribution of thefivesampletransects (A-E) and their $20 \times 20 \mathrm{~m}$ pl ots. The spacing between gridlines is $10 \mathrm{~m}$; (B) identification of sample plots and soil classification. 


\subsection{Parâmetros da Análise Estrutural}

Para descrever a estrutura da comunidade arbórea foram calculados, por espécie, os parâmetros quantitativos clássicos propostos por Mueller-Dombois \& Ellenberg (1974): densidade absoluta, frequiência absoluta, dominância absoluta expressa pela área basal, densidade relativa, freqüência relativa, dominância relativa e valor de importância. Também foram calculados o índice de diversidade de Shannon (H') e a equabilidade de Pielou (J') (Brower \& Zar, 1984). Os cálculos foram feitos pelo programa FITOPAC 2 (Shepherd, 1994).

\subsection{Análise das Correlações entre Espécies e Variáveis Ambientais}

Os três subgrupos de solos encontrados nas transeções foram comparados quanto às suas propriedades químicas e texturais. Após verificação de normalidade pelo teste de Bartlett, as variáveis de solo foram comparadas entre os três solos por meio de análises de variância, aplicando-se testes de Tukey-Kramer, tendo sido constatadas diferenças significativas entre eles (Zar, 1996). Foi utilizado o programa MINITAB for Windows versão 3.0 (McCkenzie et al., 1994). As variáveis ambientais que apresentavam os valores em porcentagem foram previamente transformadas pela expressão $\operatorname{arcsen} \sqrt{(x)} * \mathrm{k}(\mathrm{x}=$ valor a ser transformado; constante $\mathrm{k}=10^{3}$ ).

Para analisar as correlações entre a distribuição das espécies arbóreas e as variáveis ambientais foi feita uma análise de gradientes mista, pela técnica de análise de correspondência canônica, ou CCA (Ter Braak, 1988). Esta análise multivariada é atualmente a mais indicada quando o objetivo é obter uma relação mais estreita das variáveis ambientais com a abundância de espécies (Kent \& Coker, 1992; Digby \& Kempton, 1996). ACCA requer duas matrizes, uma com dados das espécies e outra com variáveis ambientais. A matriz de abundância das espécies consistiu dos valores de número de indivíduos por parcela de todas as espécies que ocorreram com mais de 15 indivíduos na amostra total, ficando a matriz final com 38 espécies e 28 parcelas. Os indivíduos menos abundantes contribuem muito pouco ou nada para a ordenação e só aumentam o volume de cálculos (Causton, 1988).

A matriz de variáveis ambientais incluiu, inicialmente, todas as variáveis edáficas, topográficas e morfométricas. Após realizar uma CCA preliminar, foram eliminadas as variáveis que produziram correlações $<0,5$ com os eixos de ordenação (teores de $\mathrm{K}, \mathrm{P}, \mathrm{Ca}, \mathrm{Mg}, \mathrm{Al}$, matéria orgânica e silte; e soma de bases e saturação por bases) ou foram redundantes entre si (cota média e borda do fragmento foram redundantes com a variável produto correspondente). Restaram, na CCA final, apenas seis variáveis ambientais: margem do rio, cota média $\times$ borda do fragmento (variável produto), desnível, areia, argila e pH. A variável produto 'cota média $\times$ borda do fragmento' foi concebida depois de muitas tentativas de combinar variáveis ambientais. As variáveis cota média e borda do fragmento não produziram correlações fortes quando usadas isoladamente, mas, como variável produto, a correlação com o primeiro eixo de ordenação foi a mais forte de todo o conjunto de variáveis utilizadas na CCA.

Dentre as inúmeras vantagens de usar a CCA, a maior delas é, com certeza, o teste de Monte Carlo (Hope, 1968), que consiste em permutar aleatoriamente as linhas da matriz de variáveis ambientais com o intuito de testar a significância da correlação entre as duas matrizes, identificando a probabilidade de acerto da relação encontrada entre as matrizes originais. A CCA e o teste de Monte Carlo foram processados pelo programa PC-ORD for Windows versão 3.0 (Mccune \& Mefford, 1997).

Para verificar as correlações entre a abundância de cada espécie em particular e as variáveis ambientais utilizadas na CCA, foram calculados coeficientes de correlação de Spearman (Zar, 1996) entre o número de indivíduos de cada uma das 38 espécies e o valor de cada uma das seis variáveis ambientais nas 28 parcelas. $\mathrm{O}$ programa utilizado foi o mesmo MINITAB for Windows versão 3.0.

\section{RESULTADOS}

\subsection{Composição Florística}

No levantamento florístico foram identificadas 165 espécies, distribuídas em 114 gêneros e 49 famílias botânicas (Quadro 1). Entre as espécies listadas, apenas uma foi identificada somente em relação ao gênero (Eugenia sp.), provavelmente por ser uma espécie nova, segundo a especialista consultada, Dra. Maria Lúcia Kawasaki, do Instituto de Botânica de São Paulo. Das 165 espécies listadas, 140 foram encontradas nas parcelas amostrais. 
Quadro 1 - Espécies arbóreas registradas no fragmento florestal do rio Capivari, município de Lavras-MG. O número de coleta é precedido de Jss naqueles coletados por Josival Santos Souza e por ESAL (número de tombo) quando coletados por outros pesquisadores

Table 1 - Tree species registered in the semideciduous forest fragment of Rio Capivari, Lavras, Southeastern Brazil. The collecting number is preceded by Jss for those collected by Josival Santos Souza, and by ESAL (registration number) for those collected by other researchers

\begin{tabular}{|c|c|}
\hline Família /Espécie & № de Coleta \\
\hline $\begin{array}{l}\text { Anacardiaceae } \\
\text { Astronium graveolens Jac. } \\
\text { Lithraea molleoides (Vell.) Engl. } \\
\text { Schinus terebinthifolius Raddi } \\
\text { Tapirira guianensis Aubl. } \\
\text { Tapirira obtusa (Benth.) Mitch. }\end{array}$ & $\begin{array}{l}\text { ESAL } 14606 \\
\text { Jss } 01 \\
\text { ESAL } 28723 \\
\text { Jss } 02 \\
\text { Jss } 03 \\
\end{array}$ \\
\hline $\begin{array}{l}\text { Annonaceae } \\
\text { Annona cacans Warm. } \\
\text { Duguetia lanceolata A.St.-Hil. } \\
\text { Guatteria nigrescens Mart. } \\
\text { Rollinia laurifolia } \text { Schltdl. } \\
\text { Rollinia sericea } \text { (R.E.Fr.) R.E.Fr. } \\
\text { Rollinia sylvatica (A.St.-Hil.) Mart. } \\
\text { Xylopia brasiliensis Spreng. } \\
\end{array}$ & \begin{tabular}{|l} 
Jss 04 \\
Jss 05 \\
Jss 06 \\
Jss 07 \\
Jss 09 \\
Jss 08 \\
ESAL 28774 \\
\end{tabular} \\
\hline $\begin{array}{l}\text { Apocynaceae } \\
\text { Aspidosperma cylindrocarpum Müll.Arg. } \\
\text { Aspidosperma parvifolium A.DC. } \\
\text { Aspidosperma ramiflorum Müll. Arg. }\end{array}$ & $\begin{array}{l}\text { ESAL } 15763 \\
\text { ESAL } 12314 \\
\text { Jss } 10\end{array}$ \\
\hline $\begin{array}{l}\text { Aquifoliaceae } \\
\text { Ilex cerasifolia } \text { Reissek }\end{array}$ & Jss 11 \\
\hline $\begin{array}{l}\text { Araliaceae } \\
\text { Dendropanax cuneatus (DC.) Decne \& Planch. }\end{array}$ & Jss 12 \\
\hline $\begin{array}{l}\text { Arecaceae } \\
\text { Syagrus romanzoffiana (Cham.) Glassm. }\end{array}$ & Jss 83 \\
\hline $\begin{array}{l}\text { Asteraceae } \\
\text { Vernonanthura diffusa (Less.) H. Rob. }\end{array}$ & ESAL 13011 \\
\hline $\begin{array}{l}\text { Bignoniaceae } \\
\text { Cybistax antisyphilitica Mart. } \\
\text { Jacaranda macrantha } \text { Cham. } \\
\text { Tabebuia ochracea } \text { (Cham.) Standl. } \\
\text { Tabebuia serratifolia } \text { (Vahl) Nichols. }\end{array}$ & \begin{tabular}{|l} 
ESAL 13345 \\
ESAL 14858 \\
JSs 13 \\
Jss 14 \\
\end{tabular} \\
\hline $\begin{array}{l}\text { Boraginaceae } \\
\text { Cordia ecalyculata Vell. } \\
\text { Cordia trichotoma (Vell.) Arrab. }\end{array}$ & \begin{tabular}{|l} 
Jss 15 \\
ESAL 15758 \\
\end{tabular} \\
\hline $\begin{array}{l}\text { Burseraceae } \\
\text { Protium spruceanum (Benth.) Engl. } \\
\text { Protium widgrenii Engl. } \\
\end{array}$ & $\begin{array}{l}\text { ESAL } 14850 \\
\text { Jss } 16 \\
\end{array}$ \\
\hline $\begin{array}{l}\text { Cecropiaceae } \\
\text { Cecropia pachystachya Trécul }\end{array}$ & ESAL 12470 \\
\hline $\begin{array}{l}\text { Celastraceae } \\
\text { Maytenus ilicifolia Mart. ex Reissek } \\
\text { Maytenus glazioviana Loes. ex Taub. } \\
\text { Salacia elliptica (Mart.) G.Don }\end{array}$ & $\begin{array}{l}\text { Jss } 115 \\
\text { Jss } 17 \\
\text { Jss } 27\end{array}$ \\
\hline
\end{tabular}

Continued...
Quadro 1, cont.

Table 1, cont.

\begin{tabular}{|c|c|}
\hline Família /Espécie & № de Coleta \\
\hline $\begin{array}{l}\text { Celtidaceae } \\
\text { Celtis iguanea (Jacq.) Sarg. }\end{array}$ & ESAL 15726 \\
\hline $\begin{array}{l}\text { Clethraceae } \\
\text { Clethra scabra Pers. }\end{array}$ & Jss 18 \\
\hline $\begin{array}{l}\text { Clusiaceae } \\
\text { Calophyllum brasiliense Cambess. } \\
\text { Vismia brasiliensis Choisy } \\
\end{array}$ & \begin{tabular}{|l} 
ESAL 12384 \\
Jss 19
\end{tabular} \\
\hline $\begin{array}{l}\text { Combretaceae } \\
\text { Terminalia glabrescens Mart. }\end{array}$ & ESAL 12178 \\
\hline $\begin{array}{l}\text { Connaraceae } \\
\text { Connarus regnellii G. Schellenb. }\end{array}$ & Jss 20 \\
\hline $\begin{array}{l}\text { Cunoniaceae } \\
\text { Lamanonia ternata Vell. }\end{array}$ & Jss 21 \\
\hline $\begin{array}{l}\text { Elaeocarpaceae } \\
\text { Sloanea monosperma Vell. }\end{array}$ & Jss 22 \\
\hline $\begin{array}{l}\text { Euphorbiaceae } \\
\text { Actinostemon concolor (Spreng.) Müll.Arg. } \\
\text { Actinostemon klotzschii (Didr.) Pax } \\
\text { Alchornea triplinervia (Spreng.) Müll.Arg. } \\
\text { Croton floribundus Spreng. } \\
\text { Pera glabrata Poepp. ex Baill. } \\
\text { Sapium glandulosum (L.) Morong } \\
\end{array}$ & \begin{tabular}{|l} 
Jss 24 \\
Jss 23 \\
ESAL 02423 \\
ESAL 12358 \\
ESAL 04121 \\
ESAL 14628 \\
\end{tabular} \\
\hline $\begin{array}{l}\text { Fabaceae Caesalpinioideae } \\
\text { Apuleia leiocarpa (Vogel) J.F. Macbr. } \\
\text { Bauhinia longifolia (Bong.) Steud. } \\
\text { Copaifera langsdorffii Desf. } \\
\text { Senna macranthera (DC. ex Collad.) Irwin \& } \\
\text { Barneby }\end{array}$ & $\begin{array}{l}\text { Jss } 38 \\
\text { Jss } 39 \\
\text { Jss } 40 \\
\text { Jss } 41\end{array}$ \\
\hline $\begin{array}{l}\text { Fabaceae Faboideae } \\
\text { Andira fraxinifolia } \text { Benth. } \\
\text { Dalbergia villosa (Benth.) Benth. } \\
\text { Lonchocarpus campestris Mart. ex Benth. } \\
\text { Lonchocarpus cultratus (Vell.) H.C. Lima } \\
\text { Machaerium brasiliense Vogel } \\
\text { Machaerium hirtum (Vell.) Stellfeld } \\
\text { Machaerium nyctitans (Vell.) Benth. } \\
\text { Machaerium stipitatum (DC.) Vogel } \\
\text { Machaerium villosum Vogel } \\
\text { Ormosia arborea (Vell.) Harms } \\
\text { Platycyamus regnellii Benth. } \\
\text { Platypodium elegans } \text { Vogel }\end{array}$ & \begin{tabular}{|l} 
Jss 42 \\
Jss 43 \\
Jss 45 \\
Jss 44 \\
Jss 47 \\
Jss 46 \\
ESAL 06016 \\
Jss 48 \\
Jss 49 \\
ESAL 12662 \\
ESAL 12217 \\
Jss 50
\end{tabular} \\
\hline $\begin{array}{l}\text { Fabaceae Mimosoideae } \\
\text { Acacia glomerosa } \text { Benth. } \\
\text { Acacia recurva } \text { Benth. } \\
\text { Albizia polycephala (Benth.) Killip } \\
\text { Inga ingoides (Rich.) Willd. }\end{array}$ & $\begin{array}{l}\text { Jss } 114 \\
\text { Jss } 51 \\
\text { Jss } 52 \\
\text { Jss } 53\end{array}$ \\
\hline
\end{tabular}

Continua... Continued... 
Quadro 1, cont.

Table 1, cont.

\begin{tabular}{|c|c|}
\hline Família /Espécie & № de Coleta \\
\hline $\begin{array}{l}\text { Fabaceae Mimosoideae } \\
\text { Inga marginata Willd. } \\
\text { Inga striata Benth. } \\
\text { Inga vera Willd. } \\
\text { Leucochloron incuriale (Vell.) Barneby \& Grimes } \\
\text { Piptadenia gonoacantha (Mart.) J.F. Macbr. }\end{array}$ & $\begin{array}{l}\text { ESAL } 13080 \\
\text { ESAL } 15108 \\
\text { ESAL } 15734 \\
\text { Jss } 54 \\
\text { ESAL } 12865\end{array}$ \\
\hline $\begin{array}{l}\text { Flacourtiaceae } \\
\text { Banara parviflora (A.Gray) Benth. } \\
\text { Casearia arborea (L.C.Rich.) Urb. } \\
\text { Casearia gossypiosperma Briq. } \\
\text { Casearia lasiophylla Eichl. } \\
\text { Casearia sylvestris } \text { Sw. } \\
\text { Xylosma ciliatifolium (Clos) Eichl. }\end{array}$ & $\begin{array}{l}\text { Jss } 25 \\
\text { ESAL } 9475 \\
\text { ESAL } 14629 \\
\text { ESAL } 9729 \\
\text { JSs } 26 \\
\text { ESAL } 12390 \\
\end{array}$ \\
\hline $\begin{array}{l}\text { Lacistemaceae } \\
\text { Lacistema hasslerianum Chodat }\end{array}$ & ESAL 9633 \\
\hline $\begin{array}{l}\text { Lauraceae } \\
\text { Cryptocarya aschersoniana Mez } \\
\text { Nectandra grandiflora Nees } \\
\text { Nectandra lanceolata } \text { Nees } \\
\text { Nectandra oppositifolia } \mathrm{Nees} \\
\text { Ocotea aciphylla (Nees) Mez } \\
\text { Ocotea brachybotra (Meisn.) Mez } \\
\text { Ocotea corymbosa (Meisn.) Mez } \\
\text { Ocotea elegans Mez } \\
\text { Ocotea odorifera (Vell.) Rohwer } \\
\text { Persea pyrifolia Nees } \\
\end{array}$ & \begin{tabular}{|l} 
Jss 28 \\
Jss 31 \\
Jss 32 \\
Jss 29 \\
Jss 33 \\
Jss 30 \\
Jss 34 \\
Jss 35 \\
ESAL 13082 \\
Jss 36 \\
\end{tabular} \\
\hline $\begin{array}{l}\text { Lecythidaceae } \\
\text { Cariniana estrellensis (Raddi) Kuntze }\end{array}$ & Jss 37 \\
\hline $\begin{array}{l}\text { Loganiaceae } \\
\text { Strychnos brasiliensis (Spreng.) Mart. }\end{array}$ & Jss 55 \\
\hline $\begin{array}{l}\text { Lythraceae } \\
\text { Lafoensia pacari A.St.-Hil. }\end{array}$ & Jss 56 \\
\hline $\begin{array}{l}\text { Malvaceae } \\
\text { Eriotheca candolleana ( K. Schum.) A. Robyns } \\
\text { Guazuma ulmifolia Lam. } \\
\text { Helicteres ovata Lam. } \\
\text { Luehea divaricata Mart. } \\
\text { Luehea grandiflora Mart. \& Zucc. } \\
\text { Luehea rufescens } \text { Benth. }\end{array}$ & $\begin{array}{l}\text { ESAL } 14928 \\
\text { Jss } 101 \\
\text { Jss } 102 \\
\text { Jss } 106 \\
\text { ESAL } 14943 \\
\text { Jss } 107\end{array}$ \\
\hline $\begin{array}{l}\text { Melastomataceae } \\
\text { Miconia sellowiana Naudin } \\
\text { Miconia trianae Cogn. }\end{array}$ & $\begin{array}{l}\text { Jss } 57 \\
\text { ESAL } 15102\end{array}$ \\
\hline $\begin{array}{l}\text { Meliaceae } \\
\text { Cabralea canjerana (Vell.) Mart. } \\
\text { Cedrela fissilis } \text { Vell. } \\
\text { Trichilia clausseni } \text { C.DC. } \\
\text { Trichilia lepidota } \text { Sw. } \\
\text { Trichilia pallida } \text { Sw. }\end{array}$ & $\begin{array}{l}\text { Jss } 59 \\
\text { ESAL } 12234 \\
\text { ESAL } 14676 \\
\text { Jss } 58 \\
\text { ESAL } 12478\end{array}$ \\
\hline
\end{tabular}

Continua...

Continued...
Quadro 1, cont.

Table 1, cont.

\begin{tabular}{|c|c|}
\hline Família /Espécie & $\mathrm{N}^{\mathrm{o}}$ de Coleta \\
\hline $\begin{array}{l}\text { Monimiaceae } \\
\text { Mollinedia widgrenii A.DC. }\end{array}$ & Jss 61 \\
\hline $\begin{array}{l}\text { Moraceae } \\
\text { Maclura tinctoria D.Don. ex Steud. } \\
\text { Sorocea bonplandii (Baill.) W.C. Burger }\end{array}$ & $\begin{array}{l}\text { ESAL } 12229 \\
\text { Jss } 62\end{array}$ \\
\hline $\begin{array}{l}\text { Myrsinaceae } \\
\text { Myrsine umbellata Mart. }\end{array}$ & Jss 63 \\
\hline $\begin{array}{l}\text { Myrtaceae } \\
\text { Blepharocalyx salicifolia (Kunth) O.Berg } \\
\text { Calycorectes acutatus (Miq.) Toledo } \\
\text { Calyptranthes brasiliensis Spreng. } \\
\text { Calyptranthes clusiifolia (Miq.) O. Berg } \\
\text { Campomanesia guazumifolia (Cambess.) O.Berg } \\
\text { Campomanesia xanthocarpa O.Berg } \\
\text { Eugenia florida DC. } \\
\text { Eugenia neomyrtifolia Sobral } \\
\text { Eugenia pluriflora DC. } \\
\text { Eugenia pyriformis Cambess. } \\
\text { Eugenia sp. (espécie nova) } \\
\text { Gomidesia affinis (Cambess.) D.Legrand } \\
\text { Myrcia fallax (Rich.) DC. } \\
\text { Myrcia multiflora (Lam.) DC. } \\
\text { Myrcia rostrata DC. } \\
\text { Myrcia tomentosa (Aubl.) DC. } \\
\text { Myrcia venulosa DC. } \\
\text { Pimenta pseudocaryophyllus (Gomes) Landrum } \\
\text { Psidium cattleyanum Sabine } \\
\text { Psidium rufum Mart. } \\
\text { Siphoneugena densiflora O.Berg }\end{array}$ & $\begin{array}{l}\text { Jss } 64 \\
\text { Jss } 65 \\
\text { Jss } 68 \\
\text { Jss } 67 \\
\text { Jss } 66 \\
\text { ESAL } 15706 \\
\text { Jss } 69 \\
\text { Jss } 70 \\
\text { Jss } 71 \\
\text { Jss } 79 \\
\text { Jss } 60 \\
\text { Jss } 72 \\
\text { ESAL } 12242 \\
\text { Jss } 73 \\
\text { ESAL } 15710 \\
\text { Jss } 76 \\
\text { Jss } 77 \\
\text { Jss } 113 \\
\text { Jss } 74 \\
\text { Jss } 80 \\
\text { Jss } 75\end{array}$ \\
\hline $\begin{array}{l}\text { Nyctaginaceae } \\
\text { Guapira opposita (Vell.) Reitz }\end{array}$ & Jss 81 \\
\hline $\begin{array}{l}\text { Olacaceae } \\
\text { Heisteria silvianii Schwacke }\end{array}$ & Jss 82 \\
\hline $\begin{array}{l}\text { Picramniaceae } \\
\text { Picramnia glazioviana Engl. }\end{array}$ & ESAL 15110 \\
\hline $\begin{array}{l}\text { Polygonaceae } \\
\text { Coccoloba warmingii Meisn. }\end{array}$ & Jss 84 \\
\hline $\begin{array}{l}\text { Proteaceae } \\
\text { Euplassa incana (Klotszch) I.M. Johnst. } \\
\text { Roupala montana Aubl. } \\
\text { Roupala paulensis Sleumer }\end{array}$ & $\begin{array}{l}\text { Jss } 56 \\
\text { Jss } 85 \\
\text { ESAL } 12127 \\
\end{array}$ \\
\hline $\begin{array}{l}\text { Rubiaceae } \\
\text { Alibertia concolor (Cham.) K.Schum. } \\
\text { Amaioua guianensis Aubl. } \\
\text { Chomelia sericea Müll.Arg. } \\
\text { Coutarea hexandra (Jacq.) K.Schum. }\end{array}$ & $\begin{array}{l}\text { ESAL } 12571 \\
\text { Jss } 90 \\
\text { Jss } 88 \\
\text { Jss } 91\end{array}$ \\
\hline
\end{tabular}

Continua

Continued... 
Quadro 1, cont Table 1, cont.

\begin{tabular}{|c|c|}
\hline Família/Espécie & № de Coleta \\
\hline \multicolumn{2}{|l|}{ Rubiaceae } \\
\hline Faramea cyanea Müll.Arg. & ESAL 12576 \\
\hline Ixora warmingii Müll.Arg. & Jss 92 \\
\hline Psychotria carthagenensis Jacq. & Jss 89 \\
\hline Randia nitida (Kunth) DC. & Jss 87 \\
\hline Rudgea viburnoides (Cham.) Benth. & ESAL 14001 \\
\hline \multicolumn{2}{|l|}{ Rutaceae } \\
\hline Galipea jasminiflora (A.St.-Hil.) Engl. & ESAL 13389 \\
\hline Metrodorea stipularis Mart. & Jss 93 \\
\hline Zanthoxylum fagara (L.) Sarg. & Jss 94 \\
\hline Zanthoxylum monogynum A.St.-Hil. & Jss 95 \\
\hline Zanthoxylum rhoifolium Lam. & ESAL 12565 \\
\hline \multicolumn{2}{|l|}{ Sapindaceae } \\
\hline Allophylus edulis (A.St.-Hil.) Radlk. ex Warm. & Jss 96 \\
\hline Cupania vernalis Cambess. & Jss 97 \\
\hline Matayba elaeagnoides Radlk. & Jss 98 \\
\hline Matayba juglandifolia (Cambess.) Radlk. & Jss 99 \\
\hline \multicolumn{2}{|l|}{ Sapotaceae } \\
\hline Chrysophyllum marginatum (Hook. \& Arn.) Radlk. & Jss 100 \\
\hline \multicolumn{2}{|l|}{ Siparunaceae } \\
\hline Siparuna guianensis Aubl. & ESAL 15097 \\
\hline Siparuna cujabana (Mart.) A.DC. & ESAL 12998 \\
\hline \multicolumn{2}{|l|}{ Styracaceae } \\
\hline Styrax camporum Pohl & Jss 103 \\
\hline Styrax latifolium Pohl & Jss 104 \\
\hline \multicolumn{2}{|l|}{ Symplocaceae } \\
\hline Symplocos pubescens Klotzsch ex Benth. & Jss 105 \\
\hline \multicolumn{2}{|l|}{ Thymelaeaceae } \\
\hline Daphnopsis brasiliensis Mart. \& Zucc. & Jss 112 \\
\hline \multicolumn{2}{|l|}{ Verbenaceae } \\
\hline Aegiphila sellowiana Cham. & Jss 108 \\
\hline \multicolumn{2}{|l|}{ Vochysiaceae } \\
\hline Callisthene major Mart. & Jss 111 \\
\hline Qualea cordata (Mart.) Spreng. & ESAL12729 \\
\hline Qualea multiflora Mart. & Jss 109 \\
\hline Vochysia tucanorum Mart. & Jss 110 \\
\hline
\end{tabular}

As famílias com maiores riquezas de espécies, com seu respectivo número de espécies entre parênteses, foram: Fabaceae (25); Myrtaceae (21); Lauraceae (10); Rubiaceae (9); Annonaceae (7); Euphorbiaceae, Flacourtiaceae e Malvaceae (6); Anacardiaceae, Meliaceae e Rutaceae (5); Bignoniaceae, Sapindaceae e Vochysiaceae (4); e Apocynaceae, Celastraceae e Proteaceae (3), que representam $34,7 \%$ da flora amostrada. Pode-se observar ainda que $49 \%$ das famílias (25) foram amostradas por uma única espécie. Os gêneros que apresentaram maiores riquezas florísticas, com o número de espécies entre parênteses, foram: Eugenia, Ocotea, Myrcia e Machaerium (5); Inga e Casearia (4); e Rollinia, Aspidosperma, Nectandra, Luehea, Trichilia e Zanthoxylum (3). Os demais gêneros (102) são representados por duas ou uma espécie, o equivalente a $89,5 \%$.

\subsection{Análise Estrutural da Comunidade Arbórea}

No total, foram amostrados 1.666 indivíduos com DAP $\geq 5,0 \mathrm{~cm}$, pertencentes a 140 espécies, 99 gêneros e 45 famílias botânicas, em uma área amostral total de 1,12 ha. A amostra apresentou um índice de Shannon de 4,258 nats/indivíduo e um índice de equabilidade de Pielou de 0,862. Foram constatadas uma área basal de $31,03 \mathrm{~m}^{2} / \mathrm{ha}$ e uma densidade de 1487 árvores/ha.

Os parâmetros quantitativos para as espécies encontram-se no Quadro 2. Copaifera langsdorffii foi a espécie com maior densidade absoluta de indivíduos (72,3/ha), seguida por Machaerium villosum (61,6), Albizia polycephala $(58,0)$, Calycorectes acutatus $(53,6) \mathrm{e}$ Protium widgrenii $(50,0)$. Estas cinco espécies, no entanto, somam apenas $19,6 \%$ da densidade relativa. As espécies com maior dominância absoluta (DoA) foram Copaifera langsdorffii $\left(3,4 \mathrm{~m}^{2} / \mathrm{ha}\right)$, Machaerium villosum $\left(2,90 \mathrm{~m}^{2} / \mathrm{ha}\right)$, Tapirira obtusa $\left(1,20 \mathrm{~m}^{2} / \mathrm{ha}\right)$, Ocotea odorifera $\left(1,10 \mathrm{~m}^{2} / \mathrm{ha}\right)$ e Albizia polycephala $\left(0,80 \mathrm{~m}^{2} /\right.$ ha). Estas cinco espécies são responsáveis por $34,1 \%$ da dominância relativa total.

O número de espécies raras, ou seja, com menos de uma árvore por hectare (sensu Kageyama \& Garanda, 1993) foi de 53 espécies ou 37,86\% do total, correspondendo a $24,28 \%$ do número de indivíduos amostrados.

\subsection{Análise das Correlações Espécie-Ambiente}

No Quadro 3 estão as médias e os desvios-padrão das propriedades químicas e granulométricas dos três subgrupos de solos (Cambissolo, Argissolo A e Argissolo B), indicando acidez elevada e toxidez por alumínio de média à alta para os três subgrupos de solos. De acordo com os padrões da EMBRAPA (1997), os teores de cálcio foram médios no Cambissolo e baixos nos Argissolos A e $\mathrm{B}$; já os de magnésio foram médios nos três subgrupos de solos, embora mais altos no Cambissolo. O fósforo e o potássio apresentaram baixos teores para ambos os solos, não havendo nenhuma diferença significativa para o primeiro. A soma de bases foi média para o Cambissolo 
e baixa para os Argissolos A e B. A saturação por bases foi baixa para o Cambissolo e muito baixa para os
Argissolos A e B. Os teores de matéria orgânica foram altos para os três subgrupos de solos.

Quadro 2 - Espécies arbóreas amostradas em 28 parcelas de $20 \times 20 \mathrm{~m}$ na Mata do Rio Capivari, Lavras-MG, com seus parâmetros quantitativos: $\mathrm{NI}=$ número de indivíduos, $\mathrm{NP}=$ número de parcelas com a espécie, $\mathrm{G}=$ área basal $\left(\mathrm{m}^{2}\right), \mathrm{D}=$ diâmetro máximo $(\mathrm{cm}), \mathrm{A}=$ altura máxima $(\mathrm{m}), \mathrm{DA}=$ densidade absoluta (indivíduos/ha), $\mathrm{FA}=$ freqüência absoluta $(\%)$, DoA $=$ dominância absoluta $\left(\mathrm{m}^{2} / \mathrm{ha}\right), \mathrm{DR}=$ densidade relativa $(\%), \mathrm{FA}=$ freqüência relativa $(\%)$, DoA $=$ dominância relativa (\%) e VI = valor de importância

Table 2 - Tree species sampled in 28 sample plots of $20 \times 20 \mathrm{~m}$ laid on Rio Capivari forest, Lavras, southeastern Brazil, with their quantitative parameters: $N I=$ number of individuals; $N P=$ number of plots with the species; $G=$ basal area $\left(m^{2}\right) ; D=$ maximum diameter (cm); $A=$ maximum height $(\mathrm{m}) ; D A=$ absolute density (individuals $/$ ha) $; F A=$ absolute frequency (\%); $D o A=$ absolute dominance $\left(\mathrm{m}^{2} / \mathrm{ha}\right) ; \mathrm{DR}=$ relative density (\%); $F A=$ relative frequency $(\%) ; D o A=$ relative dominance (\%); VI = importance value

\begin{tabular}{|c|c|c|c|c|c|c|c|c|c|c|c|c|}
\hline Espécie & NI & $\mathrm{NP}$ & $\bar{G}$ & $\bar{D}$ & $\bar{A}$ & $\overline{\mathrm{DA}}$ & FA & $\overline{D o A}$ & $\overline{\mathrm{DR}}$ & $\overline{F R}$ & DoR & VI \\
\hline Copaifera langsdorffii & 81 & 26 & 3,796 & 50,10 & 25,00 & 72,30 & 92,90 & 3,390 & 4,90 & 3,20 & 12,24 & 20,30 \\
\hline Machaerium villosum & 69 & 25 & 3,296 & 50,00 & 23,00 & 61,60 & 89,30 & 2,940 & 4,10 & 3,10 & 10,62 & 17,90 \\
\hline Albizia polycephala & 65 & 21 & 0,898 & 35,00 & 18,00 & 58,00 & 75,00 & 0,800 & 3,90 & 2,60 & 2,90 & 9,40 \\
\hline Tapirira obtusa & 47 & 15 & 1,383 & 50,90 & 17,00 & 42,00 & 53,60 & 1,200 & 2,80 & 1,90 & 4,46 & 9,10 \\
\hline Calycorectes acutatus & 60 & 20 & 0,787 & 52,80 & 18,00 & 53,60 & 71,40 & 0,700 & 3,60 & 2,50 & 2,54 & 8,60 \\
\hline Cupania vernalis & 51 & 22 & 0,807 & 34,30 & 13,00 & 45,50 & 78,60 & 0,720 & 3,10 & 2,70 & 2,60 & 8,40 \\
\hline Protium widgrenii & 56 & 16 & 0,757 & 39,50 & 14,00 & 50,00 & 57,10 & 0,680 & 3,40 & 2,00 & 2,44 & 7,80 \\
\hline Ocotea odorifera & 38 & 12 & 1,197 & 44,20 & 17,00 & 33,90 & 42,90 & 1,100 & 2,30 & 1,50 & 3,86 & 7,60 \\
\hline Tapirira guianensis & 52 & 14 & 0,792 & 32,30 & 13,00 & 46,40 & 50,00 & 0,710 & 3,10 & 1,70 & 2,55 & 7,40 \\
\hline Platycyamus regnellii & 51 & 18 & 0,602 & 31,30 & 15,00 & 45,50 & 64,30 & 0,540 & 3,10 & 2,20 & 1,94 & 7,20 \\
\hline Luehea divaricata & 37 & 18 & 0,731 & 51,10 & 13,00 & 33,00 & 64,30 & 0,650 & 2,20 & 2,20 & 2,36 & 6,80 \\
\hline Machaerium nyctitans & 36 & 13 & 0,772 & 43,00 & 23,00 & 32,10 & 46,40 & 0,690 & 2,20 & 1,60 & 2,49 & 6,30 \\
\hline Bauhinia longifolia & 38 & 19 & 0,368 & 24,10 & 15,00 & 33,90 & 67,90 & 0,330 & 2,30 & 2,40 & 1,19 & 5,80 \\
\hline Dalbergia villosa & 30 & 14 & 0,703 & 56,80 & 16,00 & 26,80 & 50,00 & 0,630 & 1,80 & 1,70 & 2,26 & 5,80 \\
\hline Matayba elaeagnoides & 38 & 18 & 0,382 & 41,40 & 12,00 & 33,90 & 64,30 & 0,340 & 2,30 & 2,20 & 1,23 & 5,70 \\
\hline Casearia sylvestris & 39 & 16 & 0,392 & 27,00 & 15,00 & 34,80 & 57,10 & 0,350 & 2,30 & 2,00 & 1,26 & 5,60 \\
\hline Actinostemon concolor & 40 & 18 & 0,294 & 29,90 & 16,00 & 35,70 & 64,30 & 0,260 & 2,40 & 2,20 & 0,95 & 5,60 \\
\hline Eugenia neomyrtifolia & 38 & 16 & 0,302 & 27,40 & 14,00 & 33,90 & 57,10 & 0,270 & 2,30 & 2,00 & 0,97 & 5,20 \\
\hline Nectandra oppositifolia & 30 & 14 & 0,439 & 38,50 & 20,00 & 26,80 & 50,00 & 0,390 & 1,80 & 1,70 & 1,42 & 5,00 \\
\hline Piptadenia gonoacantha & 21 & 10 & 0,727 & 43,90 & 23,00 & 18,80 & 35,70 & 0,650 & 1,30 & 1,20 & 2,34 & 4,80 \\
\hline Machaerium hirtum & 23 & 14 & 0,481 & 49,90 & 16,00 & 20,50 & 50,00 & 0,430 & 1,40 & 1,70 & 1,55 & 4,70 \\
\hline Platypodium elegans & 14 & 8 & 0,836 & 54,00 & 20,00 & 12,50 & 28,60 & 0,750 & 0,80 & 1,00 & 2,69 & 4,50 \\
\hline Vismia brasiliensis & 24 & 13 & 0,415 & 32,80 & 15,00 & 21,40 & 46,40 & 0,370 & 1,40 & 1,60 & 1,34 & 4,40 \\
\hline Luehea grandiflora & 19 & 7 & 0,734 & 52,80 & 18,00 & 17,00 & 25,00 & 0,660 & 1,10 & 0,90 & 2,36 & 4,40 \\
\hline Persea pyrifolia & 21 & 9 & 0,609 & 42,20 & 16,00 & 18,80 & 32,10 & 0,540 & 1,30 & 1,10 & 1,96 & 4,30 \\
\hline Nectandra grandiflora & 19 & 11 & 0,536 & 48,30 & 13,00 & 17,00 & 39,30 & 0,480 & 1,10 & 1,40 & 1,73 & 4,20 \\
\hline Calyptranthes clusiifolia & 31 & 12 & 0,106 & 13,40 & 8,00 & 27,70 & 42,90 & 0,090 & 1,90 & 1,50 & 0,34 & 3,70 \\
\hline Siphoneugena densiflora & 19 & 12 & 0,296 & 23,90 & 13,00 & 17,00 & 42,90 & 0,260 & 1,10 & 1,50 & 0,95 & 3,60 \\
\hline Guazuma ulmifolia & 16 & 10 & 0,319 & 26,40 & 14,00 & 14,30 & 35,70 & 0,280 & 1,00 & 1,20 & 1,03 & 3,20 \\
\hline Myrcia fallax & 22 & 12 & 0,087 & 13,40 & 10,00 & 19,60 & 42,90 & 0,080 & 1,30 & 1,50 & 0,28 & 3,10 \\
\hline Cryptocarya aschersoniana & 15 & 9 & 0,323 & 37,20 & 17,00 & 13,40 & 32,10 & 0,290 & 0,90 & 1,10 & 1,04 & 3,10 \\
\hline Campomanesia guazumifolia & 22 & 9 & 0,144 & 21,30 & 12,00 & 19,60 & 32,10 & 0,130 & 1,30 & 1,10 & 0,47 & 2,90 \\
\hline Chrysophyllum marginatum & 16 & 11 & 0,157 & 18,30 & 11,00 & 14,30 & 39,30 & 0,140 & 1,00 & 1,40 & 0,51 & 2,80 \\
\hline Siparuna guianensis & 16 & 9 & 0,227 & 39,20 & 16,00 & 14,30 & 32,10 & 0,200 & 1,00 & 1,10 & 0,73 & 2,80 \\
\hline Nectandra lanceolata & 11 & 7 & 0,388 & 37,00 & 13,00 & 9,80 & 25,00 & 0,350 & 0,70 & 0,90 & 1,25 & 2,80 \\
\hline Coccoloba warmingii & 17 & 8 & 0,231 & 31,80 & 11,00 & 15,20 & 0,21 & 0,200 & 1,00 & 1,00 & 0,74 & 2,80 \\
\hline Connarus regnellii & 18 & 10 & 0,124 & 23,30 & 10,00 & 16,10 & 0,11 & 0,100 & 1,10 & 1,20 & 0,40 & 2,70 \\
\hline
\end{tabular}

Continua...

Continued... 
Quadro 2, cont.

Table 2, cont.

\begin{tabular}{|c|c|c|c|c|c|c|c|c|c|c|c|c|}
\hline Espécie & $\mathrm{NI}$ & NP & G & $\mathrm{D}$ & A & DA & FA & DoA & DR & FR & DoR & VI \\
\hline Roupala montana & 11 & 8 & 0,325 & 29,90 & 15,00 & 9,80 & 0,29 & 0,300 & 0,70 & 1,00 & 1,05 & 2,70 \\
\hline Zanthoxylum monogynum & 16 & 9 & 0,186 & 28,00 & 13,00 & 14,30 & 0,17 & 0,200 & 1,00 & 1,10 & 0,60 & 2,70 \\
\hline Eugenia sp. & 13 & 10 & 0,181 & 28,70 & 17,00 & 11,60 & 0,16 & 0,200 & 0,80 & 1,20 & 0,58 & 2,60 \\
\hline Machaerium stipitatum & 16 & 11 & 0,072 & 12,10 & 11,00 & 14,30 & 0,06 & 0,100 & 1,00 & 1,40 & 0,23 & 2,60 \\
\hline Metrodorea stipularis & 18 & 6 & 0,204 & 25,50 & 16,00 & 16,10 & 0,18 & 0,200 & 1,10 & 0,70 & 0,66 & 2,50 \\
\hline Lamanonia ternata & 8 & 7 & 0,304 & 34,10 & 11,00 & 7,10 & 0,27 & 0,300 & 0,50 & 0,90 & 0,98 & 2,30 \\
\hline Gomidesia affinis & 14 & 8 & 0,055 & 11,10 & 10,00 & 12,50 & 0,05 & 0,050 & 0,80 & 1,00 & 0,18 & 2,00 \\
\hline Andira fraxinifolia & 14 & 5 & 0,168 & 24,30 & 15,00 & 12,50 & 0,15 & 0,200 & 0,80 & 0,60 & 0,54 & 2,00 \\
\hline Cabralea canjerana & 10 & 7 & 0,128 & 28,30 & 17,00 & 8,90 & 0,11 & 0,100 & 0,60 & 0,90 & 0,41 & 1,90 \\
\hline Coutarea hexandra & 9 & 9 & 0,046 & 10,80 & 10,00 & 8,00 & 0,04 & 0,040 & 0,50 & 1,10 & 0,15 & 1,80 \\
\hline Casearia arborea & 10 & 5 & 0,179 & 26,10 & 13,00 & 8,90 & 0,16 & 0,200 & 0,60 & 0,60 & 0,58 & 1,80 \\
\hline Ixora warmingii & 12 & 3 & 0,187 & 23,20 & 13,00 & 10,70 & 0,17 & 0,200 & 0,70 & 0,40 & 0,60 & 1,70 \\
\hline Cedrela fissilis & 6 & 5 & 0,212 & 29,00 & 15,00 & 5,40 & 0,19 & 0,200 & 0,40 & 0,60 & 0,68 & 1,70 \\
\hline Casearia lasiophylla & 14 & 5 & 0,051 & 8,60 & 9,00 & 12,50 & 0,05 & 0,050 & 0,80 & 0,60 & 0,16 & 1,60 \\
\hline Rollinia laurifolia & 5 & 4 & 0,222 & 36,30 & 13,50 & 4,50 & 0,20 & 0,200 & 0,30 & 0,50 & 0,71 & 1,50 \\
\hline Dendropanax cuneatus & 8 & 4 & 0,154 & 28,30 & 12,00 & 7,10 & 0,14 & 0,100 & 0,50 & 0,50 & 0,50 & 1,50 \\
\hline Psidium cattleyanum & 7 & 6 & 0,076 & 17,80 & 10,00 & 6,30 & 0,07 & 0,100 & 0,40 & 0,70 & 0,24 & 1,40 \\
\hline Ocotea brachybotra & 6 & 4 & 0,158 & 33,00 & 13,00 & 5,40 & 0,14 & 0,100 & 0,40 & 0,50 & 0,51 & 1,40 \\
\hline Inga ingoides & 5 & 4 & 0,141 & 26,00 & 14,00 & 4,50 & 0,13 & 0,100 & 0,30 & 0,50 & 0,45 & 1,30 \\
\hline Lafoensia pacari & 5 & 4 & 0,139 & 38,00 & 11,00 & 4,50 & 14,30 & 0,120 & 0,30 & 0,50 & 0,45 & 1,20 \\
\hline Blepharocalyx salicifolia & 6 & 4 & 5 & 25,50 & 0 & 5,40 & 30 & 80 & 0,40 & 0,50 & 0,27 & 1,10 \\
\hline Senna macranthera & 8 & 3 & 0,080 & 21,20 & 13,00 & 7,10 & 10,70 & 0,070 & 0,50 & 0,40 & 0,26 & 1,10 \\
\hline Eugenia florida & 8 & 4 & 0,037 & 10,40 & 8,00 & 7,10 & 14,30 & 0,030 & 0,50 & 0,50 & 0,12 & 1,10 \\
\hline Lonchocarpus campestris & 5 & 4 & 0,087 & 28,00 & 15,00 & 4,50 & 14,30 & 0,080 & 0,30 & 0,50 & 0,28 & 1,10 \\
\hline Protium spruceanum & 4 & 3 & 0,114 & 32,70 & 12,00 & 3,60 & 10,70 & 0,100 & 0,20 & 0,40 & 0,37 & 1,00 \\
\hline Clethra scabra & 3 & 2 & 0,169 & 44,30 & 11,00 & 2,70 & 7,10 & 0,150 & 0,20 & 0,30 & 0,55 & 1,00 \\
\hline Aegiphila sellowiana & 7 & 2 & 0,093 & 21,30 & 10,00 & 6,30 & 7,10 & 0,080 & 0,40 & 0,30 & 0,30 & 1,00 \\
\hline Xylosma ciliatifolium & 4 & 4 & 0,071 & 24,50 & 12,00 & 3,60 & 14,30 & 0,060 & 0,20 & 0,50 & 0,23 & 1,00 \\
\hline Casearia gossypiosperma & 5 & 4 & 0,052 & 19,70 & 12,00 & 4,50 & 14,30 & 0,050 & 0,30 & 0,50 & 0,17 & 1,00 \\
\hline Cariniana estrellensis & 4 & 4 & 0,057 & 20,70 & 12,50 & 3,60 & 14,30 & 0,050 & 0,20 & 0,50 & 0,18 & 0,90 \\
\hline Rollinia sylvatica & 5 & 4 & 0,034 & 13,70 & 9,00 & 4,50 & 14,30 & 0,030 & 0,30 & 0,50 & 0,11 & 0,90 \\
\hline Ilex cerasifolia & 5 & 4 & 0,034 & 17,20 & 15,00 & 4,50 & 14,30 & 0,030 & 0,30 & 0,50 & 0,11 & 0,90 \\
\hline Mollinedia widgrenii & 4 & 4 & 0,042 & 14,00 & 10,00 & 3,60 & 14,30 & 0,040 & 0,20 & 0,50 & 0,14 & 0,90 \\
\hline Croton floribundus & 4 & 3 & 0,073 & 20,20 & 12,00 & 3,60 & 10,70 & 0,070 & 0,20 & 0,40 & 0,24 & 0,90 \\
\hline Myrcia rostrata & 4 & 4 & 0,035 & 17,00 & 12,00 & 3,60 & 14,30 & 0,030 & 0,20 & 0,50 & 0,11 & 0,90 \\
\hline Rollinia sericea & 5 & 3 & 0,044 & 19,40 & 9,00 & 4,50 & 10,70 & 0,040 & 0,30 & 0,40 & 0,14 & 0,80 \\
\hline Myrsine umbellata & 5 & 3 & 0,043 & 14,90 & 10,00 & 4,50 & 10,70 & 0,040 & 0,30 & 0,40 & 0,14 & 0,80 \\
\hline Actinostemon klotzschii & 4 & 4 & 0,023 & 13,20 & 10,00 & 3,60 & 14,30 & 0,020 & 0,20 & 0,50 & 0,07 & 0,80 \\
\hline Ocotea corymbosa & 3 & 2 & 0,110 & 32,00 & 13,00 & 2,70 & 7,10 & 0,100 & 0,20 & 0,30 & 0,36 & 0,80 \\
\hline Annona cacans & 4 & 3 & 0,050 & 18,00 & 14,00 & 3,60 & 10,70 & 0,040 & 0,20 & 0,40 & 0,16 & 0,80 \\
\hline Guapira opposita & 4 & 4 & 0,010 & 6,10 & 7,00 & 3,60 & 14,30 & 0,010 & 0,20 & 0,50 & 0,03 & 0,80 \\
\hline Duguetia lanceolata & 6 & 2 & 0,048 & 19,30 & 12,00 & 5,40 & 7,10 & 0,040 & 0,40 & 0,30 & 0,15 & 0,80 \\
\hline Euplassa incana & 3 & 3 & 0,061 & 18,80 & 10,00 & 2,70 & 10,70 & 0,050 & 0,20 & 0,40 & 0,20 & 0,80 \\
\hline
\end{tabular}

Continua...

Continued... 
Quadro 2, cont.

Table 2, cont.

\begin{tabular}{|c|c|c|c|c|c|c|c|c|c|c|c|c|}
\hline Espécie & $\mathrm{NI}$ & NP & G & $\mathrm{D}$ & A & DA & FA & DoA & DR & FR & DoR & VI \\
\hline Inga striata & 3 & 3 & 0,050 & 19,60 & 11,00 & 2,70 & 10,70 & 0,040 & 0,20 & 0,40 & 0,16 & 0,70 \\
\hline Myrcia tomentosa & 3 & 3 & 0,047 & 18,90 & 8,00 & 2,70 & 10,70 & 0,040 & 0,20 & 0,40 & 0,15 & 0,70 \\
\hline Guatteria nigrescens & 5 & 2 & 0,041 & 15,00 & 8,00 & 4,50 & 7,10 & 0,040 & 0,30 & 0,30 & 0,13 & 0,70 \\
\hline Acacia recurva & 3 & 2 & 0,073 & 20,90 & 13,50 & 2,70 & 7,10 & 0,070 & 0,20 & 0,30 & 0,23 & 0,70 \\
\hline Sorocea bonplandii & 3 & 3 & 0,030 & 14,50 & 12,00 & 2,70 & 10,70 & 0,030 & 0,20 & 0,40 & 0,10 & 0,70 \\
\hline Randia nitida & 2 & 2 & 0,063 & 27,50 & 13,00 & 1,80 & 7,10 & 0,060 & 0,10 & 0,30 & 0,20 & 0,60 \\
\hline Styrax camporum & 4 & 2 & 0,025 & 13,50 & 7,00 & 3,60 & 7,10 & 0,020 & 0,20 & 0,30 & 0,08 & 0,60 \\
\hline Allophylus edulis & 3 & 2 & 0,039 & 17,90 & 8,00 & 2,70 & 7,10 & 0,030 & 0,20 & 0,30 & 0,12 & 0,60 \\
\hline Symplocos pubescens & 3 & 2 & 0,031 & 14,80 & 12,00 & 2,70 & 7,10 & 0,030 & 0,20 & 0,30 & 0,10 & 0,50 \\
\hline Heisteria silvianii & 3 & 2 & 0,027 & 14,30 & 7,00 & 2,70 & 7,10 & 0,020 & 0,20 & 0,30 & 0,09 & 0,50 \\
\hline Matayba juglandifolia & 3 & 2 & 0,018 & 10,40 & 9,50 & 2,70 & 7,10 & 0,020 & 0,20 & 0,30 & 0,06 & 0,50 \\
\hline Cordia ecalyculata & 2 & 2 & 0,034 & 15,30 & 9,00 & 1,80 & 7,10 & 0,030 & 0,10 & 0,30 & 0,11 & 0,50 \\
\hline Acacia glomerosa & 3 & 2 & 0,012 & 8,30 & 8,00 & 2,70 & 7,10 & 0,010 & 0,20 & 0,30 & 0,04 & 0,50 \\
\hline Calyptranthes brasiliensis & 2 & 2 & 0,027 & 13,50 & 10,00 & 1,80 & 7,10 & 0,020 & 0,10 & 0,30 & 0,09 & 0,50 \\
\hline Xylopia brasiliensis & 3 & 2 & 0,009 & 6,50 & 5,00 & 2,70 & 7,10 & 0,010 & 0,20 & 0,30 & 0,03 & 0,50 \\
\hline Trichilia lepidota & 2 & 2 & 0,020 & 13,20 & 10,00 & 1,80 & 7,10 & 0,020 & 0,10 & 0,30 & 0,06 & 0,40 \\
\hline Tabebuia serratifolia & 2 & 2 & 0,020 & 14,30 & 10,00 & 1,80 & 7,10 & 0,020 & 0,10 & 0,30 & 0,06 & 0,40 \\
\hline Psidium rufum & 2 & 2 & 0,017 & 14,00 & 11,00 & 1,80 & 7,10 & 0,020 & 0,10 & 0,30 & 0,06 & 0,40 \\
\hline Pimenta pseudocaryophyllus & 2 & 2 & 0,016 & 13,50 & 8,00 & 1,80 & 7,10 & 0,010 & 0,10 & 0,30 & 0,05 & 0,40 \\
\hline Luehea rufescens & 2 & 2 & 0,016 & 12,30 & 7,00 & 1,80 & 7,10 & 0,010 & 0,10 & 0,30 & 0,05 & 0,40 \\
\hline Lonchocarpus cultratus & 2 & 2 & 0,016 & 10,10 & 5,00 & 1,80 & 7,10 & 0,010 & 0,10 & 0,30 & 0,05 & 0,40 \\
\hline Myrcia multiflora & 2 & 2 & 0,012 & 11,00 & 11,00 & 1,80 & 7,10 & 0,010 & 0,10 & 0,30 & 0,04 & 0,40 \\
\hline Zanthoxylum fagara & 2 & 2 & 0,008 & 8,60 & 8,00 & 1,80 & 7,10 & 0,010 & 0,10 & 0,30 & 0,03 & 0,40 \\
\hline Maytenus glazioviana & 3 & 1 & 0,028 & 16,50 & 11,00 & 2,70 & 3,60 & 0,025 & 0,20 & 0,10 & 0,09 & 0,40 \\
\hline Aspidosperma ramiflor & 2 & 2 & 0,007 & 7,60 & 8,00 & 1,80 & 7,10 & 0,006 & 0,10 & 0,30 & 0,02 & 0,40 \\
\hline Eugenia pluriflora & 2 & 2 & 0,007 & 7,60 & 4,00 & 1,80 & 7,10 & 0,006 & 0,10 & 0,30 & 0,02 & 0,40 \\
\hline Helicteres ovata & 2 & 2 & 0,006 & 7,20 & 5,50 & 1,80 & 7,10 & 0,006 & 0,10 & 0,30 & 0,02 & 0,40 \\
\hline Amaioua guianensis & 2 & 2 & 0,006 & 6,50 & 5,00 & 1,80 & 7,10 & 0,005 & 0,10 & 0,30 & 0,02 & 0,40 \\
\hline Psychotria carthagenensis & 2 & 2 & 0,005 & 5,70 & 6,00 & 1,80 & 7,10 & 0,004 & 0,10 & 0,30 & 0,02 & 0,40 \\
\hline Sloanea monosperma & 2 & 2 & 0,004 & 5,30 & 3,00 & 1,80 & 7,10 & 0,004 & 0,10 & 0,30 & 0,01 & 0,40 \\
\hline Jacaranda macrantha & 1 & 1 & 0,045 & 23,90 & 12,00 & 0,90 & 3,60 & 0,040 & 0,10 & 0,10 & 0,14 & 0,30 \\
\hline Cordia trichotoma & 2 & 1 & 0,018 & 12,70 & 10,00 & 1,80 & 3,60 & 0,016 & 0,10 & 0,10 & 0,06 & 0,30 \\
\hline Campomanesia xanthocarpa & 2 & 1 & 0,009 & 7,60 & 8,00 & 1,80 & 3,60 & 0,008 & 0,10 & 0,10 & 0,03 & 0,30 \\
\hline Eugenia pyriformis & 2 & 1 & 0,006 & 7,00 & 8,00 & 1,80 & 3,60 & 0,005 & 0,10 & 0,10 & 0,02 & 0,30 \\
\hline Inga vera & 1 & 1 & 0,024 & 17,40 & 11,00 & 0,90 & 3,60 & 0,021 & 0,10 & 0,10 & 0,08 & 0,30 \\
\hline Lithraea molleoides & 1 & 1 & 0,022 & 16,50 & 7,00 & 0,90 & 3,60 & 0,019 & 0,10 & 0,10 & 0,07 & 0,30 \\
\hline Apuleia leiocarpa & 1 & 1 & 0,018 & 15,30 & 14,00 & 0,90 & 3,60 & 0,016 & 0,10 & 0,10 & 0,06 & 0,20 \\
\hline Machaerium brasiliense & 1 & 1 & 0,009 & 10,80 & 8,00 & 0,90 & 3,60 & 0,008 & 0,10 & 0,10 & 0,03 & 0,20 \\
\hline Salacia elliptica & 1 & 1 & 0,008 & 10,40 & 8,00 & 0,90 & 3,60 & 0,008 & 0,10 & 0,10 & 0,03 & 0,20 \\
\hline Strychnos brasiliensis & 1 & 1 & 0,007 & 9,70 & 6,00 & 0,90 & 3,60 & 0,007 & 0,10 & 0,10 & 0,02 & 0,20 \\
\hline Galipea jasminiflora & 1 & 1 & 0,007 & 9,50 & 5,00 & 0,90 & 3,60 & 0,006 & 0,10 & 0,10 & 0,02 & 0,20 \\
\hline Daphnopsis brasiliensis & 1 & 1 & 0,007 & 9,10 & 10,00 & 0,90 & 3,60 & 0,006 & 0,10 & 0,10 & 0,02 & 0,20 \\
\hline Leucochloron incuriale & 1 & 1 & 0,006 & 8,40 & 8,00 & 0,90 & 3,60 & 0,005 & 0,10 & 0,10 & 0,02 & 0,20 \\
\hline
\end{tabular}

Continua... Continued... 
Quadro 2, cont.

Table 2, cont.

\begin{tabular}{|c|c|c|c|c|c|c|c|c|c|c|c|c|}
\hline Espécie & NI & $\mathrm{NP}$ & $\mathrm{G}$ & $\mathrm{D}$ & $\mathrm{A}$ & $\mathrm{DA}$ & FA & DoA & DR & FR & DoR & VI \\
\hline Ocotea elegans & 1 & 1 & 0,006 & 8,40 & 6,00 & 0,90 & 3,60 & 0,005 & 0,10 & 0,10 & 0,02 & 0,20 \\
\hline Qualea multiflora & 1 & 1 & 0,004 & 7,50 & 6,00 & 0,90 & 3,60 & 0,004 & 0,10 & 0,10 & 0,01 & 0,20 \\
\hline Maytenus ilicifolia & 1 & 1 & 0,004 & 7,30 & 5,00 & 0,90 & 3,60 & 0,004 & 0,10 & 0,10 & 0,01 & 0,20 \\
\hline Banara parviflora & 1 & 1 & 0,004 & 7,20 & 8,00 & 0,90 & 3,60 & 0,004 & 0,10 & 0,10 & 0,01 & 0,20 \\
\hline Styrax latifolium & 1 & 1 & 0,004 & 7,20 & 5,00 & 0,90 & 3,60 & 0,004 & 0,10 & 0,10 & 0,01 & 0,20 \\
\hline Tabebuia ochracea & 1 & 1 & 0,004 & 7,00 & 3,50 & 0,90 & 3,60 & 0,003 & 0,10 & 0,10 & 0,01 & 0,20 \\
\hline Alibertia concolor & 1 & 1 & 0,004 & 6,80 & 5,00 & 0,90 & 3,60 & 0,003 & 0,10 & 0,10 & 0,01 & 0,20 \\
\hline Terminalia glabrescens & 1 & 1 & 0,004 & 6,80 & 5,00 & 0,90 & 3,60 & 0,003 & 0,10 & 0,10 & 0,01 & 0,20 \\
\hline Myrcia venulosa & 1 & 1 & 0,004 & 6,70 & 6,00 & 0,90 & 3,60 & 0,003 & 0,10 & 0,10 & 0,01 & 0,20 \\
\hline Vochysia tucanorum & 1 & 1 & 0,003 & 6,50 & 8,00 & 0,90 & 3,60 & 0,003 & 0,10 & 0,10 & 0,01 & 0,20 \\
\hline Rudgea viburnoides & 1 & 1 & 0,003 & 6,40 & 4,50 & 0,90 & 3,60 & 0,003 & 0,10 & 0,10 & 0,01 & 0,20 \\
\hline Lacistema hasslerianum & 1 & 1 & 0,003 & 6,20 & 4,50 & 0,90 & 3,60 & 0,003 & 0,10 & 0,10 & 0,01 & 0,20 \\
\hline Cybistax antisyphilitica & 1 & 1 & 0,003 & 5,70 & 7,00 & 0,90 & 3,60 & 0,002 & 0,10 & 0,10 & 0,01 & 0,20 \\
\hline Aspidosperma parvifolium & 1 & 1 & 0,002 & 5,40 & 3,50 & 0,90 & 3,60 & 0,002 & 0,10 & 0,10 & 0,01 & 0,20 \\
\hline Chomelia sericea & 1 & 1 & 0,002 & 4,90 & 4,00 & 0,90 & 3,60 & 0,002 & 0,10 & 0,10 & 0,01 & 0,20 \\
\hline Pera glabrata & 1 & 1 & 0,002 & 4,80 & 4,00 & 0,90 & 3,60 & 0,002 & 0,10 & 0,10 & 0,01 & 0,20 \\
\hline Alchornea triplinervea & 1 & 1 & 0,002 & 4,80 & 6,00 & 0,90 & 3,60 & 0,002 & 0,10 & 0,10 & 0,01 & 0,20 \\
\hline
\end{tabular}

Quadro 3 - Variáveis químicas e texturais de 28 amostras do solo superficial $(0-20 \mathrm{~cm})$ coletadas na Mata do Capivari, Lavras-MG. Os valores são médias \pm desvios-padrão das $N$ amostras de cada um dos três subgrupos de solo, em que as análises de variância indicaram diferenças significativas entre os solos $(P<0,05)$ e as médias seguidas de letras diferentes são significativamente diferentes em testes de Tukey $(P<0,05)$

Table 3 - Chemical and textural variables of 28 topsoil samples $(0-20 \mathrm{~cm}$ deep), collected in Rio Capivari Forest, Lavras, southeastern Brazil. Values are means \pm standard deviations of $N$ samples of each of the three soil classes, where analyses of variance indicated significant differences among soils $(P<0.05)$, with means followed by different letters being significantly different in the Tukey tests $(P<0.05)$

\begin{tabular}{|c|c|c|c|c|c|c|}
\hline \multirow{2}{*}{$\begin{array}{ll} & \text { Variável } \\
\mathrm{PH} & \end{array}$} & \multicolumn{2}{|l|}{$\begin{array}{c}\text { Cambissolo } \\
(N=8)\end{array}$} & \multicolumn{2}{|c|}{$\begin{array}{c}\text { Argissolo A } \\
(N=14)\end{array}$} & \multicolumn{2}{|c|}{$\begin{array}{c}\text { Argissolo B } \\
(N=6)\end{array}$} \\
\hline & $4,80 \pm 0,36$ & $\mathrm{a}$ & $4,34 \pm 0,17$ & $\mathrm{~b}$ & $4,92 \pm 0,19$ & $\mathrm{a}$ \\
\hline P Mehlich $\left(\mathrm{mg} / \mathrm{dm}^{3}\right)$ & $1,25 \pm 0,46$ & ns & $1,50 \pm 0,52$ & ns & $1,33 \pm 0,52$ & ns \\
\hline $\mathrm{K}\left(\mathrm{mg} / \mathrm{dm}^{3}\right)$ & $44,38 \pm 14,7$ & $\mathrm{a}$ & $29,86 \pm 5,82$ & $\mathrm{~b}$ & $40,33 \pm 15,32$ & $\mathrm{ab}$ \\
\hline $\mathrm{Ca}\left(\mathrm{cmolc} / \mathrm{dm}^{3}\right)$ & $3,95 \pm 3,39$ & $\mathrm{a}$ & $0,72 \pm 0,27$ & $\mathrm{~b}$ & $1,23 \pm 0,63$ & $\mathrm{~b}$ \\
\hline $\operatorname{Mg}\left(\mathrm{cmolc} / \mathrm{dm}^{3}\right)$ & $0,95 \pm 0,66$ & $\mathrm{a}$ & $0,36 \pm 0,35$ & $\mathrm{~b}$ & $0,72 \pm 0,53$ & $\mathrm{ab}$ \\
\hline $\mathrm{Al}\left(\mathrm{cmolc} / \mathrm{dm}^{3}\right)$ & $1,00 \pm 0,59$ & $\mathrm{~b}$ & $1,61 \pm 0,34$ & a & $0,95 \pm 0,42$ & $\mathrm{~b}$ \\
\hline Soma de bases $\left(\mathrm{cmolc} / \mathrm{dm}^{3}\right)$ & $4,99 \pm 3,43$ & $\mathrm{a}$ & $1,18 \pm 0,59$ & $b$ & $2,07 \pm 1,15$ & $\mathrm{~b}$ \\
\hline Saturação por bases, V (\%) & $30,73 \pm 17,92$ & $\mathrm{a}$ & $9,22 \pm 4,66$ & $\mathrm{~b}$ & $19,05 \pm 9,47$ & $\mathrm{ab}$ \\
\hline Matéria orgânica (dag/kg) & $4,15 \pm 0,49$ & $\mathrm{ab}$ & $3,67 \pm 0,32$ & $\mathrm{~b}$ & $4,45 \pm 0,84$ & $\mathrm{a}$ \\
\hline Argila (\%) & $30,00 \pm 4,21$ & $\mathrm{~b}$ & $37,29 \pm 4,65$ & $a b$ & $43,00 \pm 6,78$ & a \\
\hline Areia $(\%)$ & $40,88 \pm 6,73$ & $\mathrm{a}$ & $37,07 \pm 5,82$ & a & $14,50 \pm 7,97$ & $\mathrm{~b}$ \\
\hline Silte $(\%)$ & $29,12 \pm 6,31$ & $\mathrm{~b}$ & $25,64 \pm 2,24$ & $\mathrm{~b}$ & $42,50 \pm 4,51$ & $\mathrm{a}$ \\
\hline
\end{tabular}

ns = não-significativo. 
De modo geral, os Cambissolos apresentaram maior riqueza nutricional que os Argissolos. O Argissolo B diferiu do A principalmente pelo $\mathrm{pH}$ mais elevado e pelos teores mais baixos de Al e matéria orgânica no Argissolo B. Nas características texturais, observam-se teores de argila significativamente menores no Cambissolo e maiores no Argissolo B. Este último também apresentou teores de areia significativamente menores.

Os resultados da análise de correspondência canônica encontram-se no Quadro 4 e nas Figuras 2 e 3. Os autovalores (eigenvalues) dos dois primeiros eixos de ordenação foram baixos, 0,236 e 0,131, respectivamente, o que indica gradientes curtos, ou seja, que a maioria das espécies está distribuída por todo o gradiente, variando apenas a abundância de algumas delas (Ter Braak, 1995). As variâncias acumuladas para as espécies nos três primeiros eixos de ordenação também foram baixas: 12,3, 19,1 e $23,9 \%$. Estes baixos valores indicam que a ordenação deixou uma considerável variância remanescente sem explicação. Segundo Ter Braak (1988), esse resultado é normal em dados de vegetação e não compromete as análises das relações espécies-ambiente. De fato, o resultado da CCA mostrou alta correlação entre espécies e variáveis ambientais para os dois primeiros eixos de ordenação: 95,3 e 78,1\%. Além disto, o teste de permutação de Monte Carlo indicou que as abundâncias das espécies e as variáveis ambientais foram significativamente correlacionadas $(P<0,01$ para os dois primeiros eixos).

As correlações internas (intraset) entre as variáveis ambientais utilizadas e os dois primeiros eixos de ordenação estão no Quadro 4. O primeiro eixo correlacionouse mais, em termos absolutos, com a variável produto cota $\times$ borda e, em seguida, com as variáveis margem e areia. As variáveis mais correlacionadas com o segundo eixo foram o $\mathrm{pH}$ e o desnível do terreno. Desta forma, o primeiro eixo foi mais fortemente associado às variáveis ligadas à posição relativa das parcelas no relevo e no fragmento, enquanto o segundo esteve mais associado ao $\mathrm{pH}$ do solo e ao desnível topográfico. Na matriz de correlações ponderadas entre as variáveis ambientais (Quadro 4) pode-se observar que houve inter-relações fortes entre as variáveis, particularmente da variável produto cota $\times$ borda com a variável margem e com os teores de areia e argila no solo. Tal fato indica que esta variável sintética provavelmente tem uma considerável redundância ou complementaridade com outras variáveis ambientais, incluindo o regime de drenagem e as características químicas e texturais dos solos.

No diagrama de ordenação das parcelas pela CCA (Figura 2), observa-se que aquelas correspondentes ao Argissolo B foram as que melhor se discriminaram do conjunto, concentrando-se do lado esquerdo, enquanto as do Argissolo A e do Cambissolo misturaram-se do lado direito. Este padrão também pode ser visto como dois grupos distintos de parcelas, o primeiro deles em sítios topográficos mais elevados e, ou, com maior proximidade da borda do fragmento (lado esquerdo) e o segundo, mais próximo à margem do rio (lado direito). Esta dicotomia aparece como bastante associada às variáveis cota $\times$ borda e margem e aos teores de areia $\mathrm{e}$ argila dos solos. O segundo eixo da CCA discrimina as parcelas do lado direito do diagrama, principalmente em função do $\mathrm{pH}$ do solo e do desnível topográfico. As parcelas com terreno de desnível mais acentuado e com solos de $\mathrm{pH}$ mais elevado concentram-se no alto do diagrama e aquelas de tendências opostas, na parte de baixo.

Quadro 4 - Análise de correspondência canônica (CCA) da abundância de 38 espécies amostradas em 28 parcelas alocadas no fragmento florestal do rio Capivari: correlações internas (intraset) entre as variáveis ambientais e os dois primeiros eixos de ordenação e matriz de correlações ponderadas entre as variáveis ambientais

Table 4 - Canonical correspondence analysis (CCA) of the abundance of 38 species sampled in 28 plots laid on Rio Capivari Forest: intraset correlations between environmental variables and the first two ordination axes and matrix of weighted correlations between environmental variables

\begin{tabular}{|l|r|r|r|r|r|r|r|}
\hline \multicolumn{1}{|c|}{ Variável } & Eixo 1 & Eixo 2 & Cota×Borda & Margem & Areia & Argila & Desnível \\
\hline Cota×Borda & $-0,958$ & $-0,088$ & - & & & & \\
Margem & 0,789 & $-0,186$ & $-0,833$ & - & & & \\
Areia & 0,777 & 0,124 & 0,667 & 0,469 & - & & \\
Argila & $-0,578$ & $-0,425$ & 0,590 & $-0,337$ & $-0,775$ & - & \\
Desnível & 0,582 & 0,656 & $-0,532$ & 0,204 & 0,483 & $-0,583$ & - \\
PH & $-0,292$ & 0,746 & 0,062 & $-0,263$ & $-0,269$ & $-0,152$ & 0,115 \\
\hline
\end{tabular}




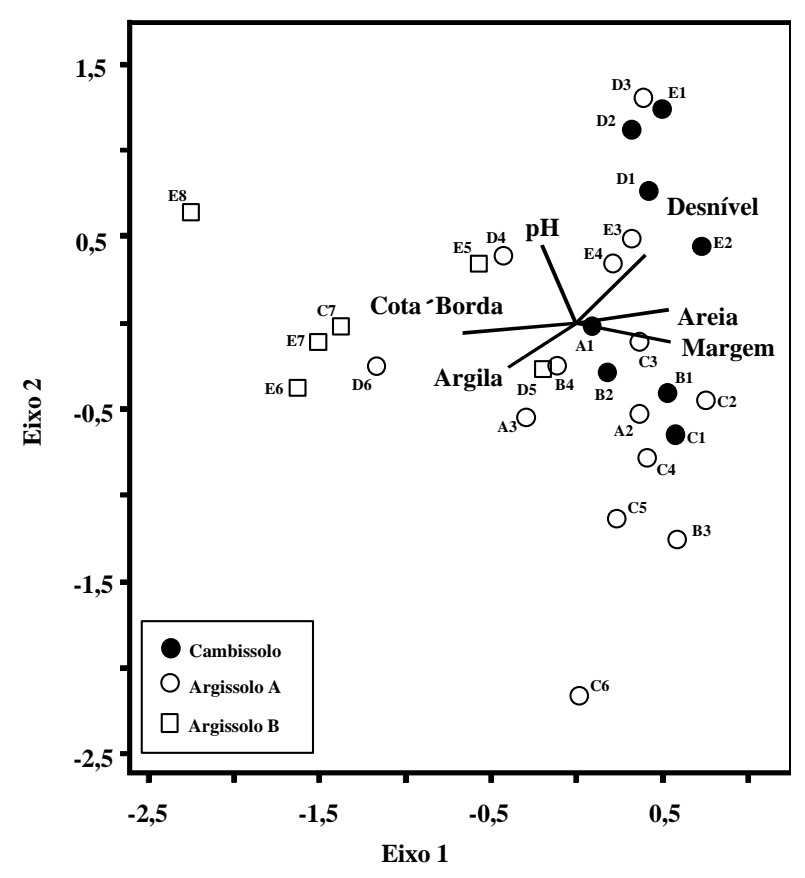

Figura 2 - Diagrama de ordenação produzido pela análise de correspondência canônica (CCA) da abundância de 38 espécies amostradas em 28 parcelas alocadas no fragmento florestal do rio Capivari. O diagrama mostra a distribuição das parcel as (codificadas conforme a Figura 1 ) e das variáveis ambientais nos dois primeiros eixos de ordenação. As parcelas estão representadas por símbol os que indicam também os subgrupos de solo. As linhas contínuas indicam a grandeza e o sentido do aumento das variáveis ambientais.

Figure 2 - Ordination diagram produced by canonical correspondence analysis of the abundances of 38 species sampled in 28 plots laid on the Capivari Forest. The diagram shows the distribution of plots (according to Figure 1) and environmental variables on the first two ordination axes. Plots are represented by symbols which also indicate the soil classes. Straight lines indicate the intensity and direction of increase of the environmental variables.

O diagrama de ordenação das espécies (Figura 3) indica que os sítios de cotas mais baixas, mais próximos do rio e de solos mais arenosos, têm associação mais forte com espécies como Connarus regnellii, Tapirira guianensis, Machaerium nyctitans, Ocotea odorifera, Calycorectes acutatus, Platycyamus regnellii, Tapirira obtusa e Cryptocarya aschersoniana. No outro extremo, os sítios de cota mais elevada e, ou, próximos à borda do fragmento e, até certo ponto, com solos de textura mais argilosa tiveram associação mais forte com espécies como Piptadenia gonoacantha, Siparuna guianensis, Casearia sylvestris, Calyptranthes clusiifolia, Chrysophylum marginatum, Machaerium hirtum, Machaerium stipitatum, Matayba elaeagnoides, Nectandra grandiflora, Machaerium villosum, Tapirira guianensis, Protium widgrenii, Nectandra oppositifolia e Luehea grandiflora.

As correlações de Spearman entre a abundância das espécies e as seis variáveis ambientais usadas na CCA encontram-se no Quadro 5. As variáveis ambientais que apresentaram maior número de correlações significativas foram cota $\times$ borda, seguidas de margem e desnível, as quais se presume serem mais representativas de variações no regime de água do solo. Os padrões são altamente coincidentes com os resultados da CCA. Desta forma, podem ser associadas com sítios mais úmidos espécies como Eugenia neomyrtifolia, Calycorectes acutatus, Cryptocarya aschersoniana, Platycyamus regnellii e Ocotea odorifera, e com sítios mais secos, Calyptranthes crusiifolia, Luehea grandiflora, Piptadenia gonoacantha e Nectandra oppositifolia.

\section{DISCUSSÃO}

\subsection{Composição Florística e Análise Estrutural da Comunidade Arbórea}

O perfil florístico encontrado para a mata do rio Capivari é bem típico das florestas semidecíduas montanas da região do alto rio Grande (Oliveira-Filho et al., 1994f, 1995), com a única particularidade da alta riqueza de espécies de Trichilia. O índice de diversidade de Shannon $\left(H^{\prime}=4,258\right.$ nats/indivíduo) é relativamente alto no contexto de outros levantamentos semelhantes feitos na região (Oliveira-Filho et al., 1994f; 1995; Van Den Berg \& Oliveira-Filho, 2000; Botrel, 2001; Rodrigues, 2001). A equabilidade $\left(J^{\prime}=0,862\right)$ é igualmente alta, indicando que há pouca concentração de abundâncias relativas em espécies dominantes. É possível que os valores relativamente altos de diversidade e equabilidade estejam relacionados com a alta heterogeneidade ambiental na área, como acontece com muitas florestas ripárias em condições de relevo acidentado (Rodrigues \& Nave, 2000). No presente caso, a heterogeneidade ambiental ficou clara nas correlações significativas entre variáveis ambientais e a distribuição da abundância das espécies na área. Entre estas variáveis misturam-se variações de umidade e fertilidade de solos a efeitos da borda do fragmento e da margem do rio, com pronunciadas variações de habitats.

R. Árvore, Viçosa-MG, v.27, n.2, p.185-206, 2003 


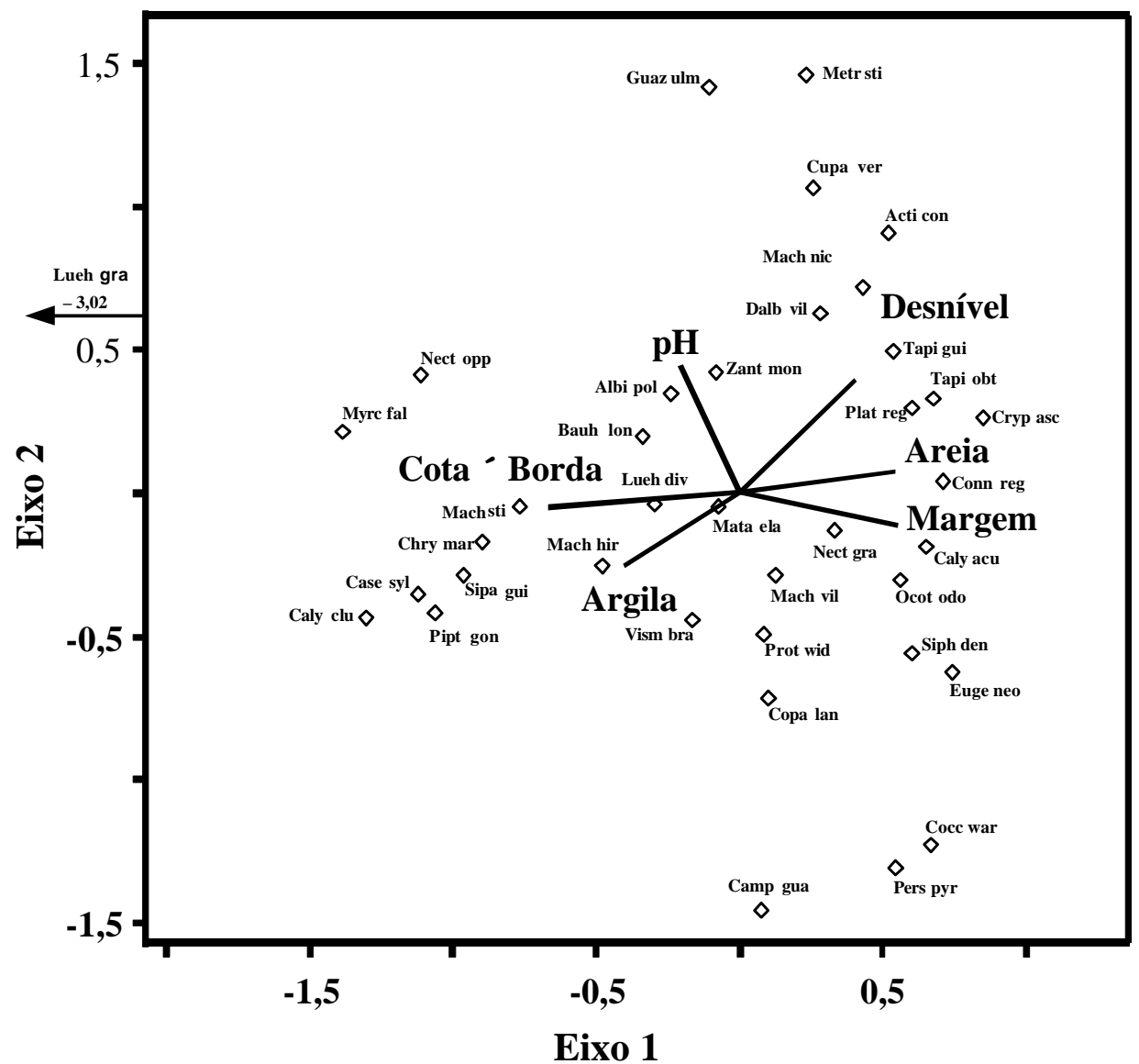

Figura 3 - Diagrama de ordenação produzi do pela análise de correspondência canônica (CCA) da abundância de 38 espécies amostradas em 28 parcel as al ocadas no fragmento florestal do rio Capivari. O diagrama mostra a distribuição das espécies e das variáveis ambientais nos dois primeiros eixos de ordenação. As espécies são identificadas pelas suas iniciais (vide nomes completos no Quadro 5). As linhas contínuas indicam a grandeza e o sentido de aumento das variáveis ambientais.

Figure 3 - Ordination diagram produced by canonical correspondenceanalysis of theabundances of 38 species sampled in 28 plots laid on the Capivari forest. The diagram shows the distribution of species and environmental variables on the first two ordination axes. The species are identified by their initials (see full names in Table 5). Straight lines indicate the intensity and direction of increase of the environmental variables.

Quando se compara com levantamentos realizados na região, empregando o mesmo critério de inclusão (DAP $\geq 5 \mathrm{~cm}$ ), constata-se que a área basal da Mata do Capivari $\left(31,03 \mathrm{~m}^{2} / \mathrm{ha}\right)$ foi bem superior à da Reserva Florestal da UFLA (Oliveira-Filho et al., 1994a), de $19,77 \mathrm{~m}^{2} / \mathrm{ha}$, mas semelhante à dos fragmentos da Mata da Ilha, em Ingaí (Botrel, 2001), de 29,31 $\mathrm{m}^{2} / \mathrm{ha}$; e Mata do Galego, em Luminárias (Rodrigues 2001), de $28,33 \mathrm{~m}^{2} / \mathrm{ha}$. A densidade da Mata do Capivari foi de 1.487 árvores/ha, também superior à da Reserva da UFLA, de 1.295 árvores/ha. Pode-se especular que a área basal e a densidade mais baixas da Reserva da UFLA podem estar ligadas à menor fertilidade dos solos, à baixa disponibilidade de água e às severas perturbações sofridas no passado (Oliveira-Filho et al., 1994b, 1997b). As outras florestas tiveram densidade superior, como a Mata da Ilha e a Mata do Galego, com 2.683 e 1.830 árvores/ ha, respectivamente.

Ao comparar esses resultados com os dos fragmentos estudados na região por Carvalho et al. (1996a), Oliveira-Filho et al. (1995, 1997a), Van Den Berg \& Oliveira-Filho (1999, 2000), Botrel (2001) e Rodrigues (2001), constatou-se não haver muita semelhança entre as comunidades arbóreas, o que indica que os fragmentos 
Quadro 5 - Coeficientes da correlação de Spearman, com sua significância, entre as 38 espécies e as seis variáveis ambientais usadas na $\mathrm{CCA} . \mathrm{C} \times \mathrm{B}=\operatorname{cota} \times$ borda. Espécies ordenadas por $\mathrm{C} \times \mathrm{B}$ decrescente

Table 5 - Spearman correlation coefficients, with their significance, among the 38 species and the six environmental variables used in $C C A$. $C \times B=$ elevation $\times$ edge. Species ordered by decreasing $C \times B$

\begin{tabular}{|c|c|c|c|c|c|c|}
\hline Espécie & $\mathrm{C} \times \mathrm{B}$ & Margem & Desnível & Argila & Areia & $\mathrm{pH}$ \\
\hline Calyptranthes clusiifolia & $0,723 * *$ & $-0,520 * *$ & $-0,456 *$ & $0,553 * *$ & $-0,532 * *$ & $-0,130 \mathrm{~ns}$ \\
\hline Luehea grandiflora & $0,654 * *$ & $-0,554 * *$ & $-0,481 * *$ & $0,538 * *$ & $-0,622 * *$ & $-0,437 *$ \\
\hline Casearia sylvestris & $0,478 * *$ & $-0,395 *$ & $-0,458 *$ & $0,280 \mathrm{~ns}$ & $-0,325 \mathrm{~ns}$ & $-0,128 \mathrm{~ns}$ \\
\hline Piptadenia gonoacantha & $0,443 *$ & $-0,435 *$ & $-0,212 \mathrm{~ns}$ & $0,293 \mathrm{~ns}$ & $-0,129 \mathrm{~ns}$ & $-0,010 \mathrm{~ns}$ \\
\hline Nectandra oppositifolia & $0,377 *$ & $-0,391 *$ & $-0,108 \mathrm{~ns}$ & $0,181 \mathrm{~ns}$ & $-0,372 \mathrm{~ns}$ & $-0,400 *$ \\
\hline Chrysophyllum marginatum & $0,318 \mathrm{~ns}$ & $-0,186 \mathrm{~ns}$ & $-0,444 *$ & $0,232 \mathrm{~ns}$ & $-0,099 \mathrm{~ns}$ & $-0,090 \mathrm{~ns}$ \\
\hline Siparuna guianensis & $0,285 \mathrm{~ns}$ & $-0,199 \mathrm{~ns}$ & $-0,042 \mathrm{~ns}$ & $0,286 \mathrm{~ns}$ & $-0,045 \mathrm{~ns}$ & $0,323 \mathrm{~ns}$ \\
\hline Luehea divaricata & $0,231 \mathrm{~ns}$ & $-0,263 \mathrm{~ns}$ & $0,209 \mathrm{~ns}$ & $-0,093 \mathrm{~ns}$ & $-0,066 \mathrm{~ns}$ & $0,182 \mathrm{~ns}$ \\
\hline Myrcia fallax & $0,222 \mathrm{~ns}$ & $-0,052 \mathrm{~ns}$ & $-0,216 \mathrm{~ns}$ & $0,123 \mathrm{~ns}$ & $-0,199 \mathrm{~ns}$ & $-0,243 \mathrm{~ns}$ \\
\hline Vismia brasiliensis & $0,105 \mathrm{~ns}$ & $0,117 \mathrm{~ns}$ & $-0,192 \mathrm{~ns}$ & $0,176 \mathrm{~ns}$ & $-0,128 \mathrm{~ns}$ & $0,086 \mathrm{~ns}$ \\
\hline Zanthoxylum monogynum & $0,059 \mathrm{~ns}$ & $-0,343 \mathrm{~ns}$ & $0,409 *$ & $-0,251 \mathrm{~ns}$ & $0,237 \mathrm{~ns}$ & $-0,061 \mathrm{~ns}$ \\
\hline Bauhinia longifolia & $0,057 \mathrm{~ns}$ & $-0,279 \mathrm{~ns}$ & $0,356 \mathrm{~ns}$ & $-0,365 \mathrm{~ns}$ & $0,091 \mathrm{~ns}$ & $-0,099 \mathrm{~ns}$ \\
\hline Machaerium hirtum & $0,029 \mathrm{~ns}$ & $0,020 \mathrm{~ns}$ & $-0,042 \mathrm{~ns}$ & $0,100 \mathrm{~ns}$ & $-0,066 \mathrm{~ns}$ & $0,076 \mathrm{~ns}$ \\
\hline Guazuma ulmifolia & $-0,009 \mathrm{~ns}$ & $-0,229 \mathrm{~ns}$ & $0,272 \mathrm{~ns}$ & $-0,115 \mathrm{~ns}$ & $0,043 \mathrm{~ns}$ & $-0,334 \mathrm{~ns}$ \\
\hline Albizia polycephala & $-0,047 \mathrm{~ns}$ & $-0,045 \mathrm{~ns}$ & $0,129 \mathrm{~ns}$ & $-0,186 \mathrm{~ns}$ & $0,047 \mathrm{~ns}$ & $-0,257 \mathrm{~ns}$ \\
\hline Machaerium stipitatum & $-0,054 \mathrm{~ns}$ & $0,025 \mathrm{~ns}$ & $0,220 \mathrm{~ns}$ & $-0,054 \mathrm{~ns}$ & $-0,227 \mathrm{~ns}$ & $-0,171 \mathrm{~ns}$ \\
\hline Copaifera langsdorffii & $-0,093 \mathrm{~ns}$ & $0,119 \mathrm{~ns}$ & $0,115 \mathrm{~ns}$ & $0,001 \mathrm{~ns}$ & $0,282 \mathrm{~ns}$ & $0,538 * *$ \\
\hline Metrodorea stipularis & $-0,096 \mathrm{~ns}$ & $-0,164 \mathrm{~ns}$ & $0,287 \mathrm{~ns}$ & $-0,369 \mathrm{~ns}$ & $0,117 \mathrm{~ns}$ & $-0,248 \mathrm{~ns}$ \\
\hline Protium widgrenii & $-0,107 \mathrm{~ns}$ & $0,278 \mathrm{~ns}$ & $-0,178 \mathrm{~ns}$ & $0,141 \mathrm{~ns}$ & $-0,358 \mathrm{~ns}$ & $-0,073 \mathrm{~ns}$ \\
\hline Nectandra grandiflora & $-0,155 \mathrm{~ns}$ & $0,077 \mathrm{~ns}$ & $0,095 \mathrm{~ns}$ & $-0,124 \mathrm{~ns}$ & $-0,022 \mathrm{~ns}$ & $-0,104 \mathrm{~ns}$ \\
\hline Campomanesia guazumifolia & $-0,162 \mathrm{~ns}$ & $0,218 \mathrm{~ns}$ & $-0,127 \mathrm{~ns}$ & $0,171 \mathrm{~ns}$ & $0,109 \mathrm{~ns}$ & $0,157 \mathrm{~ns}$ \\
\hline Machaerium villosum & $-0,167 \mathrm{~ns}$ & $0,099 \mathrm{~ns}$ & $0,133 \mathrm{~ns}$ & $0,112 \mathrm{~ns}$ & $-0,085 \mathrm{~ns}$ & $-0,056 \mathrm{~ns}$ \\
\hline Dalbergia villosa & $-0,198 \mathrm{~ns}$ & $-0,073 \mathrm{~ns}$ & $0,514 * *$ & $-0,286 \mathrm{~ns}$ & $0,196 \mathrm{~ns}$ & $-0,132 \mathrm{~ns}$ \\
\hline Connarus regnellii & $-0,221 \mathrm{~ns}$ & $0,143 \mathrm{~ns}$ & $0,379 *$ & $-0,223 \mathrm{~ns}$ & $0,334 \mathrm{~ns}$ & $0,284 \mathrm{~ns}$ \\
\hline Persea pyrifolia & $-0,264 \mathrm{~ns}$ & $0,300 \mathrm{~ns}$ & $0,041 \mathrm{~ns}$ & $-0,106 \mathrm{~ns}$ & $0,106 \mathrm{~ns}$ & $0,339 \mathrm{~ns}$ \\
\hline Tapirira guianensis & $-0,302 \mathrm{~ns}$ & $-0,047 \mathrm{~ns}$ & $0,571 * *$ & $-0,442 *$ & $0,399 *$ & $0,002 \mathrm{~ns}$ \\
\hline Machaerium nyctitans & $-0,303 \mathrm{~ns}$ & $0,065 \mathrm{~ns}$ & $0,391 *$ & $-0,322 \mathrm{~ns}$ & $-0,046 \mathrm{~ns}$ & $-0,254 \mathrm{~ns}$ \\
\hline Matayba elaeagnoides & $-0,313 \mathrm{~ns}$ & $0,129 \mathrm{~ns}$ & $0,208 \mathrm{~ns}$ & $-0,364 \mathrm{~ns}$ & $0,205 \mathrm{~ns}$ & $-0,107 \mathrm{~ns}$ \\
\hline Siphoneugena densiflora & $-0,335 \mathrm{~ns}$ & $0,318 \mathrm{~ns}$ & $0,175 \mathrm{~ns}$ & $-0,352 \mathrm{~ns}$ & $0,465 *$ & $0,272 \mathrm{~ns}$ \\
\hline Coccoloba warmingii & $-0,344 \mathrm{~ns}$ & $0,297 \mathrm{~ns}$ & $0,042 \mathrm{~ns}$ & $-0,343 \mathrm{~ns}$ & $0,290 \mathrm{~ns}$ & $0,346 \mathrm{~ns}$ \\
\hline Cupania vernalis & $-0,361 \mathrm{~ns}$ & $0,152 \mathrm{~ns}$ & $0,494 * *$ & $-0,425 *$ & $0,335 \mathrm{~ns}$ & $-0,285 \mathrm{~ns}$ \\
\hline Ocotea odorifera & $-0,437 *$ & $0,392 *$ & $0,271 \mathrm{~ns}$ & $-0,112 \mathrm{~ns}$ & $0,213 \mathrm{~ns}$ & $0,113 \mathrm{~ns}$ \\
\hline Tapirira obtusa & $-0,462 *$ & $0,310 \mathrm{~ns}$ & $0,343 \mathrm{~ns}$ & $-0,393 *$ & $0,467 *$ & $0,062 \mathrm{~ns}$ \\
\hline Actinostemon concolor & $-0,502 * *$ & $0,274 \mathrm{~ns}$ & $0,524 * *$ & $-0,356 \mathrm{~ns}$ & $0,216 \mathrm{~ns}$ & $-0,257 \mathrm{~ns}$ \\
\hline Platycyamus regnellii & $-0,522 * *$ & $0,341 \mathrm{~ns}$ & $0,496 * *$ & $-0,277 \mathrm{~ns}$ & $0,177 \mathrm{~ns}$ & $0,045 \mathrm{~ns}$ \\
\hline Eugenia neomyrtifolia & $-0,577 * *$ & $0,642 * *$ & $0,282 \mathrm{~ns}$ & $-0,379 *$ & $0,418 *$ & $0,248 \mathrm{~ns}$ \\
\hline Cryptocarya aschersoniana & $-0,612 * *$ & $0,472 *$ & $0,280 \mathrm{~ns}$ & $-0,365 \mathrm{~ns}$ & $0,211 \mathrm{~ns}$ & $-0,141 \mathrm{~ns}$ \\
\hline Calycorectes acutatus & $-0,645 * *$ & $0,431 *$ & $0,569 * *$ & $-0,511 * *$ & $0,486 * *$ & $0,115 \mathrm{~ns}$ \\
\hline
\end{tabular}

$*, P<0,05 ; * *, P<0,01 ;$ ns = não-significativo $N=28$ parcelas de $20 \times 20 \mathrm{~m}$ 
de floresta semidecídua da região podem apresentar diferenças florísticas e estruturais marcantes. Este fato é muito relevante do ponto de vista da conservação, pois vários fragmentos pequenos espalhados na paisagem podem encerrar comunidades muito distintas, não devendo ser tratados como amostras semelhantes de uma totalidade antes homogênea. Essa é a realidade atual da região do alto rio Grande, onde a alta heterogeneidade ambiental certamente correspondia à grande variação florística e estrutural das florestas, variação esta certamente representada de forma imperfeita pelos atuais fragmentos, que, por isto, merecem rigorosa conservação.

Além disso, o alto número de espécies raras indica que muitas populações podem vir a sofrer sérias dificuldades de conservação a longo prazo.

\subsection{Análise das Correlações Espécie-Ambiente}

A variação das propriedades do solo ao longo de uma catena pode ser causada por variações nas taxas de sedimentação ou erosão superficial e na composição do material sedimentado ou exportado (Oliveira-Filho et al., 1994b). Resende et al. (1988) afirmaram que nos solos em topografia íngreme as perdas e os ganhos são grandes diante das elevadas taxas de erosão superficial. Muitas vezes o escoamento superficial dos excessos hídricos promove a remoção das partículas mais leves do solo, que são depositadas na parte mais baixa da encosta, fazendo surgir um gradiente de textura mais fina encosta abaixo. Contudo, no presente caso, a textura dos solos foi mais grossa nas parcelas mais baixas e próximas à margem do rio. É possível que a textura mais arenosa na margem do rio seja provocada por cheias excepcionais e ocasionais, durante as quais o rio depositaria sedimentos arenosos. Além disto, o fragmento está localizado na curva interna do rio, onde a velocidade da água cai, diminuindo a capacidade de carrear material e incrementando a sedimentação.

Os setores topográficos mais baixos na área de estudo apresentam um terreno de várzea alta, com drenagem boa a moderada, não sujeito a encharcamento ou alagamentos sazonais, o que é comum em matas ciliares (Jacomine, 2000). O Cambissolo existente nessa área apresenta maior quantidade de nutrientes minerais, provavelmente por estar mais próximo da margem do rio e na parte mais baixa do relevo, tornando-a uma área importadora de sedimentos, matéria orgânica e nutrientes trazidos pelas cheias do rio ou transportados pela água superficial e subterrânea em movimento descendente na encosta. O Argissolo, por sua vez, não sofre maiores interferências do rio, por estar localizado em sítios mais elevados e declivosos. As perdas de material para as partes mais baixas podem ter contribuído para empobrecer seu conteúdo nutricional.

Apesar das variações significativas da fertilidade química dos solos com o relevo, é bem possível que seja o regime de água o principal fator ambiental associado à distribuição das espécies arbóreas na área, conforme já detectado em outras matas ciliares (Van Den Berg \& Oliveira-Filho, 1999; Oliveira-Filho et al., 1994c, 1994b, 1997a; Schiavini, 1997; Silva-Junior et al., 1996; SilvaJunior, 1997). A variável cota $\times$ borda e margem apresentaram as mais fortes correlações com o primeiro eixo de ordenação da CCA e o maior número de correlações significativas com a abundância das espécies em particular (correlações de Spearman). A variável produto cota $\times$ borda representa também, indiretamente, o regime de água no solo na forma de um déficit hídrico potencial. Quanto mais alta a cota, mais forte a drenagem, e quanto mais forte o efeito borda, mais os solos tendem a perder umidade (Kapos et al., 1997; Bierregard et al., 1992; Camargo \& Kapos, 1995; Murcia, 1995). Desta maneira, a variável produto combinou os dois efeitos, de forma que o efeito borda potencializou o déficit hídrico presumido nas cotas mais altas e incrementou-o nas cotas mais baixas. Pode-se concluir que as análises multivariadas resumiram não somente os gradientes de fertilidade e textura do solo nos setores topográficos (cotas), mas também, de forma implícita, um gradiente de regime hídrico dos solos. Esta problemática poderia ser mais bem elucidada se a variável umidade do solo e, ou, o nível do lençol freático tivessem sido registrados.

As tendências observadas nas correlações entre distribuição das espécies e variáveis ambientais, em uma certa área, necessitam de repetições em outros locais, para assim caracterizarem as espécies com maior segurança quanto ao habitat preferencial (Oliveira-Filho et al., 1994a). Algumas tendências detectadas neste estudo já foram registradas por outros autores. Por exemplo, as espécies Protium widgrenii, Machaerium stipitatum, Machaerium villosum, Casearia sylvestris, Nectandra oppositifolia, Siparuna arianeae, Calyptranthes clusifolia, Chrysophyllum marginatum e Luehea grandiflora mostraram preferência por sítios mais secos e pobres em nutrientes, próximos à borda do fragmento. O mesmo comportamento foi encontrado para estas espécies em outras matas ciliares do alto e médio rio 
Grande (Oliveira-Filho et al., 1995). Contudo, há casos difíceis. Van Den Berg \& Oliveira-Filho (1999) e Oliveira-Filho et al. (1994a) também observaram que Ocotea odorifera tem preferência por cotas mais baixas ou solos mais úmidos, em fragmentos de matas ciliares do alto rio Grande. Entretanto, em outro estudo, OliveiraFilho et al. (1995) associaram a mesma espécie a solos menos úmidos. Outro caso antagônico é oferecido por Calycorectes acutatus, que apresentou preferência por locais mais úmidos no presente estudo e comportamento contrário em estudos realizados por Oliveira-Filho et al. (1994c, 1995). A interação das espécies com o ambiente vai muito além dessas informações pontuais, exigindo maior cuidado na interpretação de análises, principalmente nas generalizações. Kent \& Coker (1992) alertam que estudos descritivos como este são meramente exploratórios e geradores de hipóteses, podendo apenas direcionar futuros estudos experimentais.

\section{CONCLUSÕES}

O fragmento florestal do rio Capivari apresenta considerável heterogeneidade ambiental condicionada, principalmente, pelas forte variações de topografia e solos e pela influência das bordas do fragmento. Esta heterogeneidade ambiental possivelmente reflete-se na diversidade de espécies, relativamente alta no contexto das florestas regionais, e também influi nos padrões de distribuição das abundâncias das espécies arbóreas. A baixa encosta apresenta solos mais úmidos e mais ricos em nutrientes e é caracterizada por espécies como Eugenia neomyrtifolia, Calycorectes acutatus, Cryptocarya aschersoniana, Platycyamus regnellii $\mathrm{e}$ Ocotea odorifera. A alta encosta, com solos mais secos, mais pobres em nutrientes e mais sujeitos ao efeito borda, tem como espécies características Calyptranthes crusiifolia, Luehea grandiflora, Piptadenia gonoacantha e Nectandra oppositifolia.

\section{REFERÊNCIAS BIBLIOGRÁFICAS}

ANGIOSPEM PHYLOGENY GROUP - APG. An ordinal classification for the families of flowering plants. Annals of the Missouri Botanical Garden, v. 85, n. 4, p. 531-553, 1998.

BARBOSA, L. M. SIMPÓSIO SOBRE MATA CILIAR. 1989, Campinas. Anais... Campinas: Fundação Cargil, 1989. $335 \mathrm{p}$.
BIERREGAARD, R.O. et al. The biological dynamics of tropical rain forest fragments. Bioscience, v. 42, n. 4, p. 859-866, 1992.

BOTREL, R. T. Fragmentação florestal no município de Ingaí, MG: composição florística, estrutura da comunidade arbórea e etnobotânica. 2001. $186 \mathrm{f}$. Dissertação (Mestrado em Engenharia Florestal) Universidade Federal de Lavras, Lavras, 2001.

BROWER, J. E.; ZAR, J. H. Field and laboratory methods for general ecology. Dubuque: W. M. C. Brow, 1984. $226 \mathrm{p}$.

CAMARGOS, J. L. C.; KAPOS, V. Complex edge effects on soil moisture and microclimate in Central Amazonian Forest. Journal of Tropical Ecology, v. 11, n. 2, p. 208211, 1995.

CARVALHO, D. A.; OLIVEIRA-FILHO, A. T.; VILELA, E. A. Flora arbustivo-arbórea de mata ripária do Médio Rio Grande (Conquista, Estado de Minas Gerais). Cerne, v. 2, n. 2, p. 48-68, 1996a.

CARVALHO, D. A.; OLIVEIRA-FILHO, A. T.; VILELA, E. A. Florística e fitossociologia da vegetação arbustivoarbórea de mata ripária do Baixo Paranaíba (Santa Vitória, Minas Gerais). Daphne, v. 6, n. 1, p. 60-68, 1996 b.

CARVALHO, D. A. et al. Estudos florísticos e fitossociológicos em remanescentes de florestas ripárias do Alto São Francisco e Bacia do Rio Doce - MG. Belo Horizonte: CEMIG, 1999. 39 p. (Boletim técnico, CDD 33.7).

CARVALHO, D. A. et al. Florística e estrutura da vegetação arbórea de um fragmento semidecidual às margens do reservatório da Usina Hidréletrica Dona Rita (Itambé do Mata Dentro, MG). Acta Botânica Brasilica, v. 14, n. 1, p. $37-55,2000$.

CAUSTON, D. R. An introduction to vegetation analysis, principles and interpretation. London: Unwin Hyman, 1988. $342 \mathrm{p}$.

FUNDAÇÃO CENTRO TECNOLÓGICO DE MINAS GERAIS - CETEC. Diagnóstico ambiental do Estado de Minas Gerais. Belo Horizonte, 1983. 158 p. (Série de publicações Técnicas).

DAVIDE, A. C. SIMPÓSIO MATA CILIAR: ciência e tecnologia. 1999, Lavras. Anais... Lavras: Universidade Federal de Lavras, 1999. 235 p.

DYGBY, P. G. N.; KEMPTON, R. A. Multivariate analysis of ecology comunities. London: Chapman e Hall, 1996. 206 p. (Population in Comunity Biology Series).

R. Árvore, Viçosa-MG, v.27, n.2, p. 185-206, 2003 
EITEN, G. Brazilian "Savannas". In: HUNNTLEY, B. J.; WALKER, B. H. Ecology of tropical savanna. Berlin: Verlag, 1982. p. 25-47.

EMPRESA BRASILEIRA DE PESQUISA AGROPECUÁRIA - EMBRAPA. Centro Nacional de Pesquisa de Solos. Manual de métodos de análises de solo. 2.ed. Rio de Janeiro, 1997. 212 p.

EMPRESA BRASILEIRA DE PESQUISA AGROPECUÁRIA - EMBRAPA. Centro Nacional de Pesquisa de Solos. Sistema brasileiro de classificação de solos. Rio de Janeiro, 1999.

GIBBS, P. E.; LEITÃO-FILHO, H. F.; ABBOT, R. J. Application of the point - centred quarter method in a floristic survey of an area of gallery forest at Mogi Guaçu, SP, Brazil. Revista Brasileira de Botânica, v. 3, n. 1/2, p. 17-22, 1980.

HOPE, A. C. A. A. A. Simplified Monte Carlo significance test procedure. Journal of the Royal Statistical Society Series B, v. 30, n. 3, p. 582-598, 1968.

IMAÑA-ENCINAS, J.; KLEINN, C. INTERNATIONAL SYMPOSIUM ON ASSESSEMENT AND MONITORING OF FORESTS IN TROPICAL DRY REGIONS WITH SPECIAL REFERENCE TO GALLERY FORESTS. Brasília, 1997. Proceedings... Brasília: Universidade de Brasília, 1997. 378p.

JACOMINE, P. K. T. Solos sob matas ciliares. In: RODRIGUES, R. R.; LEITÃO-FILHO, H. F. Matas ciliares: conservação e recuperação. São Paulo, 2000. p. 27-31.

KAGEYAMA, P.; GANDARA, F. B. Dinâmica de populações de espécies arbóreas implicações para o manejo e a conservação. In: SIMPÓSIO DE ECOSSISTEMAS DA COSTA BRASILEIRA, 1993, São Paulo. Anais... São Paulo: USP, 1993. v. 3. p. 1-12.

KAPOS, V.; CAMARGOS, J. L. C.; DANDE, G. Edge related changes in environment and plant response due to forest fragmentation in Central Amazonia. In.: LAURANCE, W. F.; BIERREGAARD, R. O. Tropical forest remnants: ecology, management and conservation of fragmented communities. Chicago: The university of Chicago Press, 1997. p. 45-54.

KENT, M.; COKER, P. Vegetation description and analysis, a practical approach. London: Belhaven, 1992. $363 \mathrm{p}$.

LAURENCE, W. F. et al. Rain forest fragmentation and the dynamics of Amazonian tree communities. Ecology, v. 79, n. 6 , p. 2032-2040, 1998.

R. Árvore, Viçosa-MG, v.27, n.2, p.185-206, 2003
LEITÃO-FILHO, H. F. Considerações sobre a florística de florestas tropicais e sub-tropicais do Brasil. IPEF, n. 35, p. 41-46, 1987.

LIMA, W. P.; ZAKIA, M. J. B. Hidrologia de matas ciliares. In.: RODRIGUES, R. R.; LEITÃO-FILHO, H. F. Matas ciliares: conservação e recuperação. São Paulo, 2000. p. 33-44,

MALCOLM, J. R. Edge effects in central Amazonian forest fragments. Ecology, v. 75, n. 6, p. 2438-2445, 1994.

McCUNE, B.; MEFFORD, M. J. PC-ORD Multivariate analysis of ecological data, version 3.0. MjM Software Desing. Oregon: Glaneden Beach, 1997.

McKENZIE, J.; SCHAEFER, R. L.; FARBER, E. MINITAB for windows release 10.1. Massachusetts: Addison Wesley Reading Massachusetts, 1994. 425 p.

MEIRA-NETO, J. A. et al. Estrutura de uma floresta estacional semidecidual aluvial em área diretamente afetada pela Usina Hidrelétrica de Pilar, Ponte Nova, Zona da Mata de Minas Gerais. Revista Árvore, v. 21, n. 2, p. 213-219, 1997a.

MEIRA-NETO, J. A. et al. Estrutura de uma floresta estacional semidecidual submontana em área diretamente afetada pela Usina Hidrelétrica de Pilar, Ponte Nova, Zona da Mata de Minas Gerais. Revista Árvore, v. 21, n. 3, p. 337-344, 1997 b.

MEIRA-NETO, J. A. et al. Estrutura de uma floresta estacional semidecidual insular em área diretamente afetada pela Usina Hidrelétrica de Pilar, Ponte Nova, Zona da Mata de Minas Gerais. Revista Árvore, v. 21, n. 4, p. 493-500, 1997c.

MEIRA-NETO, J. A. et al. Estrutura de uma floresta estacional semidecidual insular em área diretamente afetada pela Usina Hidrelétrica de Pilar, Guaraciaba, Zona da Mata de Minas Gerais. Revista Árvore, v. 22, n. 1, p. 179-184, 1998.

MELLO-BARRETO, H. L. Regiões fotogeográficas de Minas Gerais. Boletim Geográfico, n. 14, p. 14-28, 1942.

MUELLER-DOMBOIS, D.; ELLENBERG, H. Aims and methods of vegetation ecology. New York: Wiley \& Sons, 1974. 574 p.

MURCIA, C. Edges effects in fragmented forest: implications for conservation. Trends in Ecology and Evolution, v. 10, p. 58-62, 1995.

OLIVEIRA-FILHO, A. T.; MACHADO, J. N. M. Composição florística de uma floresta semidecídua montana na Serra de São José, Tiradentes, Minas Gerais. Acta Botanica Brasilica, v. 7, n. 2, p. 71-88, 1993. 
OLIVEIRA-FILHO, A. T. et al. Estrutura fitossociológica e variáveis ambientais em um trecho da mata ciliar do córrego dos Vilas Boas, Reserva Biológica do Poço Bonito, Lavras (MG). Revista Brasileira de Botânica, v. 17, n. 1, p. 67$85,1994 a$.

OLIVEIRA-FILHO, A. T.; SCOLFORO, J. R.; MELLO, J. M. Composição florística e estrutura comunitária de um remanescente de floresta semidecídua montana em Lavras (MG). Revista Brasileira de Botânica, v. 17 n. 2, p. 159174, 1994b.

OLIVEIRA-FILHO, A. T. et al. Effects of soils and topography on the distribution of tree species in a tropical riverine forest in south-eastern Brazil. Journal of Tropical Ecology, v. 10, n. 4, p. 483-508, 1994c.

OLIVEIRA-FILHO, A. T. et al. Differentiation of streamside and upland vegetation in an area of montane semideciduous forest in southeastern Brazil. Flora, v. 189, n. 4, p. 287-305, 1994d.

OLIVEIRA-FILHO, A. T. et al. Effect of flooding regime and understorey bamboos on the physiognomy and tree species composition of a tropical semideciduous forest in Southeastern Brazil. Vegetatio, v. 113, n. 2, p. 99-124, 1994e.

OLIVEIRA-FILHO, A. T. et al. Comparison of the woody flora and soils of six areas of montane semideciduous forest in southern Minas Gerais, Brazil. Journal of Botany, v. 51, n. 3, p. 355-389, $1994 \mathrm{f}$.

OLIVEIRA-FILHO, A. T. et al. Estudos florísticos e fitossociológicos em remanescentes de matas ciliares do Alto e Médio Rio Grande. Belo Horizonte: CEMIG, 1995. 27 p. (Boletim Técnico, 11.106-MA/PA-013)

OLIVEIRA-FILHO, A. T. et al. Tree species distribution along soil catenas in a riverside semideciduous forest in Southeastern Brazil. Flora, v. 192, n. 1, p. 47-64, 1997a.

OLIVEIRA-FILHO, A. T.; MELLO, J. M.; SCOLFORO, J. R. S. Effects of past disturbance and edges on tree community structure and dynamics within a fragment of tropical semideciduous forest in south-eastern Brazil over a five-year period (1987-1992). Plant Ecology, v. 131, n. 1, p. $45-66,1997 b$.

OLIVEIRA-FILHO, A. T.; CURI, N.; VILELA, E. A.; CARVALHO, D. A. Effects of canopy gaps, topography and soils on the distribution of woody species in a central Brazilian deciduous dry forest. Biotropica, v. 30, n. 3, p. $362-375,1998$.

RESENDE, M.; CURI, N.; SANTANA, D. P. Pedologia e fertilidade do solo: interações e interpretações. Brasília: Ministério da Agricultura. Lavras: UFLA/FAEPE, 1988. 83 p.
RODRIGUES, L. A. Estudo florístico e estrutural da comunidade arbustiva e arbórea de uma floresta em Luminárias, MG, e informações etnobotânicas da população local. 2001. 184 f. Dissertação (Mestrado em Engenharia Florestal) - Universidade Federal de Lavras, Lavras, 2001.

RODRIGUES, R. R. Análise estrutural de formações florestais ripárias. In: SIMPÓSIO SOBRE MATAS CILIARES, 1., 1989, Anais... Campinas: Fundação Cargil, 1989. p. 99-119.

RODRIGUES, R.R. Análise de um remanescente de vegetação natural às margens do Rio Passa Cinco, Ipeúna - SP. 1991. 325 f. Tese (Doutorado em Ecologia) Universidade de Campinas, Campinas, 1991.

RODRIGUES, R. R.; NAVE, A. G. Heterogeneidade florística das matas ciliares. In.: RODRIGUES, R. R; LEITÃO-FILHO, H. F. Matas ciliares: conservação e recuperação. São Paulo: 2000. p. 45-71.

SCHIAVINI, I. Environmental characterization and groups of species in gallery forests. In. INTERNATIONAL SYMPOSIUM ON ASSESSMENT AND MONITORING OF FORESTS IN TROPICAL DRY REGIONS WITH SPECIAL REFERENCE TO GALLERY FORESTS, 1997, Brasília. Proceedings... Brasília: UnB, 1997. p. 107-113.

SHEPHERD, G. J. FITOPAC: manual do usuário. Campinas: Universidade de Campinas, 1994. 25 p.

SILVA-JUNIOR, M.C. Relationships between the tree communities of the Pitoco, Monjolo and Taquara gallery forest and environmental factors. In: INTERNATIONAL SYMPOSIUM ON ASSESSMENT AND MONITORING OF FOREST IN TROPICAL DRY REGIONS WITH SPECIAL REFERENCE TO GALLERY FOREST, 1997, Brasília. Proceedings... Brasília: UnB, 1997. p. 287-298.

SILVA-JUNIOR, M. C.; FURLEY, P. A.; RATTER, J. A. Variation in the tree communities and soils with slope in gallery forest, Federal District, Brazil. In. ANDERSON, M. G.; BROOKS, S. M. Advances in hillslope processes. London: John Wiley \& Sons, 1996. v. 1, p. 451-469.

SOCIEDADE BRASILEIRA DE BOTÂNICA. CONGRESSO NACIONAL DE BOTÂNICA, 56.; SIMPÓSIO SOBRE MATA CILIAR, 2., 1995, Ribeirão Preto. Anais.... Ribeirão Preto: USP/SBB, 1995. 416 p.

TER BRAAK, C.J.F. The analysis of vegetation environment relationships bay canonical correspondence analysis. Vegetatio, v. 69, n. 3, p. 69-77, 1988.

R. Árvore, Viçosa-MG, v.27, n.2, p.185-206, 2003 
TER BRAAK, C. J. F. Ordenation. In: JONGMAN, R. H. G.; TER BRAAK, C. J. F.; van TONGEREN, O. F. R. Data analysis in community and landscape ecology. Cambrigde: Cambrigde University, 1995. p. 91-173.

van den BERG, E.; OLIVEIRA-FILHO, A. T. Spatial partitioning among tree species within an area of tropical montane gallery forest in Southeastern Brazil. Flora, v. 194, p. 249-246, 1999.

van den BERG, E.; OLIVEIRA-FILHO, A. T. Composição florística e estrutura fitossociológica de uma floresta ripária em Itutinga, MG, e comparação com outras áreas. Revista Brasileira de Botânica, v. 22, n. 3, p. 231-253, 2000.

VELOSO, H. P.; RANGEL FILHO, A. L. R.; LIMA, J. C. A. Classificação da Vegetação Brasileira Adaptada a um Sistema Universal. Rio de Janeiro-RJ: FIBGE, 1991.
VILELA, E. A.; OLIVEIRA-FILHO, A. T.; CARVALHO, D. A. Fitossociologia de floresta ripária do Baixo Rio Grande, Conquista-MG. Revista Árvore, v. 23, n. 4, p. 423-433, 1999.

VILELA, E. A. et al. Estudos florísticos e fitossociológicos em remanescentes de florestas ripárias do Baixo Rio Paranaíba e Alto Rio São Francisco. Belo Horizonte: CEMIG, 1998. 23 p. (Boletim Técnico, 01000GE/PA-1)

VILELA, E. A.; RAMALHO, M. A. P. Análise das Temperaturas e Precipitações Pluviométricas de Lavras-MG. Ciência e Prática, v. 3, n.1 , p. 71-79, 1979.

ZAR, J. H. Biostatistical analysis. New Jersey: PrenticeHall, 1996. 